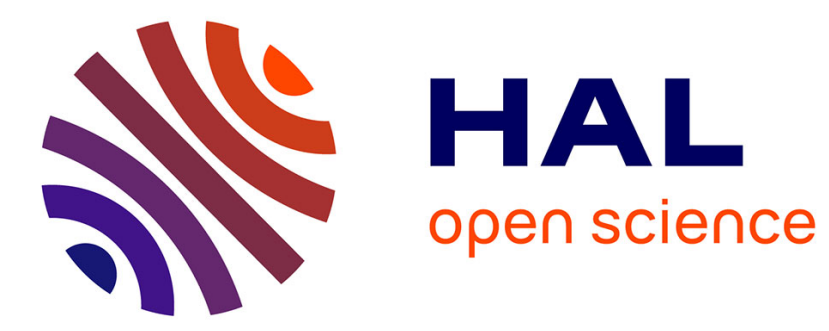

\title{
Measurements and wall modeled LES simulation of trailing edge noise caused by a turbulent boundary layer
}

B. Greschner, Julien Grilliat, Marc C. Jacob, F. Thiele

\section{To cite this version:}

B. Greschner, Julien Grilliat, Marc C. Jacob, F. Thiele. Measurements and wall modeled LES simulation of trailing edge noise caused by a turbulent boundary layer. International Journal of Aeroacoustics, 2010, 9 (3), pp.329-355. 10.1260/1475-472X.9.3.329 . hal-00566042

\section{HAL Id: hal-00566042 \\ https://hal.science/hal-00566042}

Submitted on 8 Jun 2012

HAL is a multi-disciplinary open access archive for the deposit and dissemination of scientific research documents, whether they are published or not. The documents may come from teaching and research institutions in France or abroad, or from public or private research centers.
L'archive ouverte pluridisciplinaire HAL, est destinée au dépôt et à la diffusion de documents scientifiques de niveau recherche, publiés ou non, émanant des établissements d'enseignement et de recherche français ou étrangers, des laboratoires publics ou privés. 


\title{
Measurements and wall modeled LES simulation of trailing edge noise caused by a turbulent boundary layer
}

\author{
Björn Greschner ${ }^{1}$, J. Grilliat ${ }^{2}$, M.C. Jacob ${ }^{2}$ and F. Thiele ${ }^{1}$ \\ 1/nstitut für Strömungsmechanik und Technische Akustik, Technische Universität Berlin, \\ Müller-Breslau-Str. 11, D-10623 Berlin \\ ${ }^{2}$ Centre Acoustique du LMFA, UMR CNRS 5509 - Ecole Centrale de Lyon - \\ Université Claude-Bernard Lyon I, F-69134 Ecully Cedex \\ Greschner@cfd.tu-berlin.de, Julien.Grilliat@ec-lyon.fr,MarcJacob@ec-lyon.fr. \\ Frank.Thiele@cfd.tu-berlin.de
}

Received July 9, 2009; Revised September 18, 2009; Accepted January 18, 2010

\begin{abstract}
A successful comparison between CFD-CAA and measurements of trailing edge noise is shown for a highly loaded and cambered NACA 5510 airfoil at a chord based Reynolds number of aprox. 1 million placed in a quiet low Mach number flow. The simulation is based on a new variant of the DES - the Improved Delayed Detached Eddy Simulation (IDDES).

The flow is fully attached to the airfoil and therefore only the small turbulent boundary structures that interact with the trailing edge generate significant broadband noise in the far field. The IDDES approach is designed to extend the LES region of the original DES approach (hybrid RANS/LES) from Spalart et. al. (1997) to the turbulent boundary layer, as proposed first by Travin et. al. in 2006. The non-zonal blending occures therefore inside the boundary layer the RANS model acts as a wall model for the LES. The actual work shows the capabilities of this novel approach for the simulation of broadband noise for attached flows. The simulation is compared to measurements from the EC Lyon including PIV and LDA data around the airfoil and unsteady on-wall pressure measurements near the trailing edge. Far field computations are carried out by applying the Ffowcs-Williams and Hawkings analogy to the unsteady wall pressure field and compared to acoustic measurements as well as to a far field prediction based on a trailing edge noise model that is applied to the experimental aerodynamic pressure field.
\end{abstract}

\section{INTRODUCTION}

Selfnoise is one of the major noise sources encountered in turbomachinary by-pass flows. Although selfnoise is also generated by the outlet guide vanes (OGV) trailing edges, most of the selfnoise is produced by the fan itself due to its high speed motion. Fan selfnoise is generated both at the blade tips as discussed by Jacob et al. [11], Camussi et al. [3] and at blade trailing edges (TE). In [11], the tip noise source is found to compete with the TE-noise source on a short airfoil and attemps are made to relate 
the radiated sound field to unsteady flow mechanisms based on various causality techniques [14] including wavelet based approaches following the concepts described in Camussi et al. [4]. Therefore, for long span airfoils, the TE is probably the dominant selfnoise source. In recent years, TE modeling underwent two trends, semi-analytical modeling and fully numeric modeling. The semi-analytical approach combines selfnoise broadband models based on gust theories [1] to RANS input. As discussed by Roger and Moreau in their review paper [23, 22], the analytical modeling of TE-noise is an old topic that recently progressed significantly as existing wall pressure spectra models [28] designed for non-zero pressure gradient boundary layers were revisited [9] and [25, 26]. As a result, analytical models can now be applied to flow statistics obtained from RANS computations, assuming convection velocities and spanwise coherence scales.

The fully numerical approach is based on unsteady CFD simulations of the flow field around the airfoil that is coupled to a time domain acoustic analogy, e.g. the Ffowcs-Williams and Hawkings analogy (FWH) or a linearised Euler equations. The first approach was undertaken by Wang et al. [35] with an incompressible LES computation of a low Mach number $(\mathrm{Ma} \approx 0.1)$ flow past a controlled-diffusion airfoil and compared to an experimental data set obtained at ECL [21]. Compared to Wang et al. the present investigation shows higher Mach number $(\mathrm{Ma} \approx 0.2)$ and Reynolds number $\left(R e_{c} \approx 930000\right)$ and a compressible Detached Eddy Simulation (DES) is performed.

The Detached Eddy Simulation (DES) approach is based on the idea of combining RANS and LES turbulence models. It has become increasingly popular in recent years, since DES requires a reduced computational effort in comparison to genuine LES, while retaining much of the physical accuracy of the LES method. The basic concept of DES was published in 1997 [32] and was based on the popular Spalart-Allmaras (SA) oneequation turbulence model (accordingly refered to as 'DES97'). The peculiarity of a DES approach consists in using a single turbulence model, which behaves like a subgridscale model in regions where the grid density is fine enough for a LES, and like a RANS model in regions where it is not. The self consistent formulation of this non-zonal approach is the key benefit in the development of a future 'every day' industrial tool.

A number of studies demonstrate advantages of DES over unsteady RANS methods for flows with massive separation, e.g. in [12], where the attached boundary layer is treated with the original RANS model and the separated regions with LES. In the present self noise configuration only turbulent boundary structures and no detached flow exists that causes noise, therefore a LES or DNS would be recommended for these types of problems. Therfore the standard DES97 approach is not targeted to producing any reasonable result (in meanings of resolved boundary layer flow), because the use of the LES mode is prohibited in the boundary layer. The new Improved Delayed Detached Eddy Simulation (IDDES) or wall-modelled LES is designed to extend the LES region into the turbulent boundary layer, as proposed first by Travin et al. [33] in 2006. With LES-like grids near the wall the non-zonal blending happens therefore inside the boundary layer - the RANS model acts as a wall model for the LES. The major advantage of the IDDES for the simulation of complex problems, e.g. turbomachinary flows, is an additional degree of freedom in grid generation with respect to LES. One can choose the area of interest (= major broadband noise source regions) and creates there a 
fine, LES-like grid. In the rest of the domain one is free to coarsen the mesh to a RANS-grid. This clearly demonstrates the advantage of the idea of the non-zonal IDDES approach over the pure LES for complex problems. The basic functionality of the IDDES was successfully demonstrated by Travin et al. [33], Shur et al. [31] and at ISTA by Mockett et al. [20,19] for a wide range of simple cases, such like periodic channel flows and the backward facing step. The test of the functionality of the IDDES on applied cases with the prediction of broadband noise is the novelety in the present investigation.

The paper consists of four parts. The first part contains a brief description of the self noise experiment investigated in the EU-project PROBAND by the ECL. The second part describes of the numerical basics of the IDDES method including the simulation details that are conducted in EU-project PROBAND by ISTA. This is followed by two separated sections related to the aerodynamic and aeroacoustic analysis of the simulation results compared to the experiment.

\section{FLOW CONFIGURATION AND EXPERIMENTAL SETUP}

The experiment is carried out in the anechoic room $(10 \mathrm{~m} \times 8 \mathrm{~m} \times 8 \mathrm{~m})$ of the Laboratoire de Mécanique des Fluides et d'Acoustique (LMFA), a joint CNRS-ECLUCB Lyon-I laboratory located at the Ecole Centrale de Lyon. Air is supplied by a high speed, subsonic, anechoic wind tunnel at Mach numbers ranging up to 0.3. The set-up is shown in Fig. 1. Before reaching the duct exit, the air is accelerated by a convergent nozzle from a $560 \mathrm{~mm} \times 560 \mathrm{~mm}$ cross-section to the $450 \mathrm{~mm}$ wide and $200 \mathrm{~mm}$ high test section. In the test section, the air flows as a semi open jet into the core of which a NACA 5510 profile (5\% camber, 10\% thickness) with a $200 \mathrm{~mm}$ chord and $200 \mathrm{~mm}$ span is attached between two horizontal plates. The airfoil is mounted onto a wooden disk, which allows to tuning the angle of attack. A glass window is mounted into the lower plate allowing for PIV and LDA measurements in the vicinity of the airfoil. The reference velocity at the exit of the wind tunnel is $U_{0}=70 \mathrm{~m} / \mathrm{s}$, and the turbulence level $u^{\prime} / U_{0}$ is about $0.7 \%$.

The chord-based Reynolds number is $R e_{c} \approx 930000$. For these inflow parameters, the reference configuration is obtained with an $\alpha=15^{\circ}$ angle of attack. This results into a high load but the airfoil geometry prevents the flow to separate.

\section{Measurements}

The experiment was conducted as part of the fan tip flow and noise experimental campaign reported in [11] and provided a large data set that will not be described in the present paper. Measurements referred to in this paper include:

- PIV measurements in the mid- span plane, with a La Vision system and two fast high resolution CCD cameras $(1280 \times 1024$ pixels each $)$ with $35 \mathrm{~mm}$ lenses and interferometric filters. Their axes are normal to the light sheet. The cameras are located next to each other in order to provide pictures from a $250 \times 105 \mathrm{~mm}^{2}$ rectangular area surrounding the whole airfoil with a good resolution. Images are post-processed with the Davies software. The cameras are placed beneath the glass 


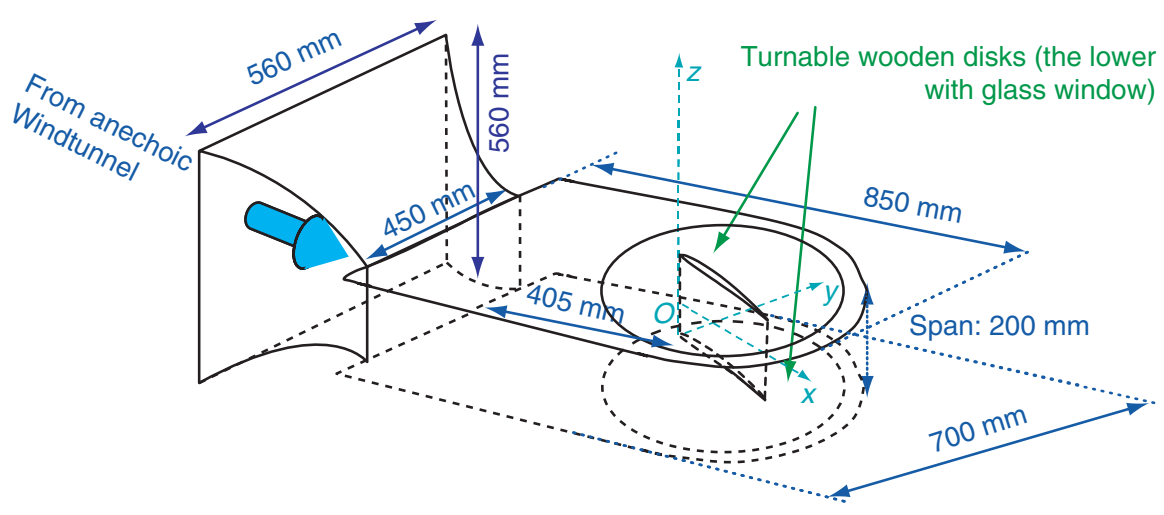

Figure 1: Experimental setup showing the convergent nozzle and the NACA 5510 airfoil with the supporting plates.

window whereas the Laser-sheets are directed horizontally first toward the suction side and then towards the pressure side. The velocity fields are computed using a $32 \times 32$ pixels interrogation window and $50 \%$ overlap that corresponds to a 1.5 $\times 1.6 \mathrm{~mm}^{2}$ area in the image. The resolution is fine enough to avoid significant peak-locking effects and the interrogation zone is both large enough to ensure a good correlation between the camera images and small enough to obtain a well resolved velocity field. The delay between 2 images is about $40 \mu s$. The flow is seeded with heated paraffin (vapour) injected upstream of the wind tunnel. The time resolution of the method is limited by the characteristics of both the Laser system and the camera. In the present case it is of the order of $4 \mathrm{~Hz}$.

- Both single and cross-wire anemometry using a Dantec anemometer with Dantec wires, to characterize the incoming flow measurements around the airfoil in the midspan and in the wake. Signals are sampled at $10 \mathrm{kHz}$ for the mean flow statistics and at $45 \mathrm{kHz}$ for the velocity spectra.

- LDA measurements that are carried out in the mid-span plane with a Dantec dualbeam, backscatter Laser Doppler Anemometer (LDA) system. Two pairs of beams are used for two-dimensional velocity measurements. They are supplied by the green line $(514.5 \mathrm{~nm})$ and the blue line $(488 \mathrm{~nm})$ of a Spectra Physics $4 \mathrm{~W}$ argon-ion Laser source. The beams of each pair undergo a relative frequency shift of $40 \mathrm{MHz}$ in a Bragg cell. The four beams are guided to the flow with an optical fibre which is terminated by a focusing lens with a focal length of $400 \mathrm{~mm}$. The beams of each pair have a mutual angle of $9^{\circ}$. For a measurement of the stream-wise and crossstream velocity components, each Laser beam makes a $4.5^{\circ}$ angle with the span-wise direction in the plane of the corresponding velocity component. The size of the measurement volume (i.e. the spatial resolution) is about $110-120 \mu \mathrm{m}$ whereas its length in the spanwise direction is $2.3-2.5 \mu \mathrm{m}$. The fringe spacing is about 5.0-5.3 $\mu \mathrm{m}$. The backscattered beams are focused by the same lens and sent through an optical fibre onto photomultipliers. The signals are then treated by two 


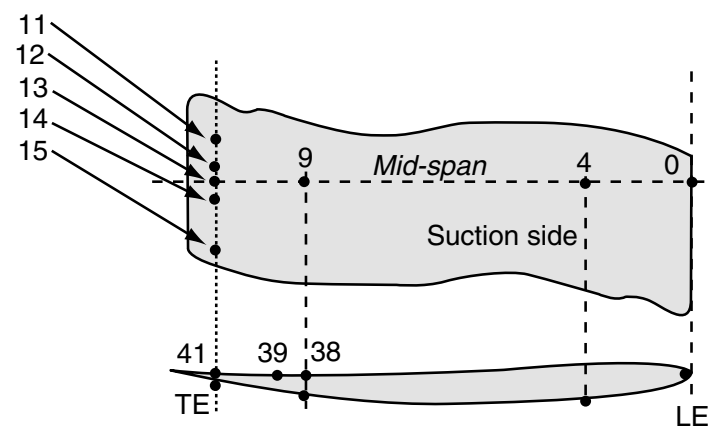

Figure 2: Unsteady pressure probe locations: suction side probes 11 to 15 are located at $97.5 \%$ chord respectively at $6 \mathrm{~mm}, 1 \mathrm{~mm}, 0 \mathrm{~mm},-2 \mathrm{~mm}$ and $12 \mathrm{~mm}$ from mid-span. Probe 41 is facing probe 13 . Other probes are located at mid-span: probes 9 and 38 are at $77.5 \%$ chord on either side of the airfoil, probe 39 is at $85 \%$ chord on the pressure side and probe 4 is at $25 \%$ chord.

Dantec real-time signal Analysers and post-processed based on $0^{\text {th }}$ order re-sampling. The seeding material is the same as that used for the PIV measurements.

- Steady and unsteady pressure measurements on the airfoil and the lower plate, including the gap: the sampling rate is $64 \mathrm{kHz}$ and the time series are long enough to perform 500 averages of 8192 point FFT's; this is enough to obtain a statistical error of less than about $1-2 \%$ on the coherence between 2 signals; the measurements are carried out with a remote microphone technique described by Roger and Perennes [24]; the sensors used are B\&K type 4935 ICP 1/4" microphones that are pre-amplified by a PXI system; they are connected to the wall measurement $0.5 \mathrm{~mm}$ diameter pinholes via narrow tubes. The probes used specifically for the self-noise measurements are located along the mid-span chord mostly on the suction side downstream quarter chord of the airfoil (see Fig. 2). Steady pressure probes are not all shown on this figure.

- Far field measurements that are performed in the mid-span plane, at about $1.7 \mathrm{~m}$ from the airfoil leading edge. For this purpose, two B\&K type 4191 1/2" microphones and B\&K 2669 preamplifiers are placed at each side of the airfoil. The microphones are turned around the airfoil in far field conditions above $f_{\min } \approx 250 \mathrm{~Hz}$.

\section{NUMERICAL METHODS AND SETUP}

In this section a brief description of the used methods and simulation tools is given. The wall-modeled LES (IDDES) is based on a Compact Explicit Algebraic Stress Turbulence Model (CEASM) which is built on a two-equation $k-\varepsilon$ model from Lien and Lechziner [17]. The compressible IDDES is used to calculate the unsteady flow field around the airfoil and the data are feed into a standard Ffowcs-Williams and Hawkings (FWH) [8] code for the calculation of the noise in the far field. 


\subsection{ELAN flow solver}

The unsteady, aerodynamic field is computed by using an in-house, finite-volume code that solves either the unsteady Reynolds-averaged or spatially filtered Navier-Stokes equations employing a RANS or Large Eddy Simulation, respectively. A time implicit formulation is used with second order accuracy both in space and in time. All scalar quantities, as well as the Cartesian components of tensorial quantities are stored in the cell centres of arbitrarily curvilinear, semi-structured grids that can fit very complex geometries with the desired local refinement level. Linear momentum equations are solved sequentially, with the pressure field computed at each time step via a separate iterative procedure based on a pressure-correction scheme of the SIMPLE type with an additional compressible convection term as described by Ferziger \& Peric [7]. The set of compressible equations is completed with an equation for the total enthalpy and the ideal gas law. A generalised Rhie \& Chow interpolation is used to avoid an odd-even decoupling of pressure, velocity and Reynolds-stress components. The system of equations is solved by an iterative method, the well known Stone's SIP solver.

\subsection{Improved delayed detached eddy simulation}

The DES method was developed for the simulation of separated flows with the treatment of the entire boundary layer using RANS. This non zonal, hybrid technique was introduced by Spalart et al. [32] in 1997 (DES97) for the SA turbulence model in order to combine the strengths of RANS and LES. The fundamental advantages of this hybrid approach are manifest both in terms of computational costs and of accuracy in the prediction of complex wall bounded flows. Furthermore, the high performance of LES in the outer turbulent regions is maintained in the DES technique. The blending is done by modifying the length scale $L_{R A N S}$ of the turbulence model. This model length scale is substituted by the DES length scale $L_{D E S}$, that is defined similarly to an implicit filter in LES:

$$
\Delta=\max \left(\Delta_{x}, \Delta_{y}, \Delta_{z}\right) \text { and } L_{D E S}=\min \left(l_{R A N S}, C_{D E S} \Delta\right) .
$$

The method was later generalised to be applicable to any RANS model by Travin et al. [34]. The further investigations on the DES approach shows some problems for critcal cases, e.g. 'modeled stress depletion' (MSD) that can lead to 'grid induced separation' (GIS) and the activation of the near wall damping terms of the underlying turbulence model in the LES regions. These problems are adressed by the development of the Delayed Detached Eddy Simulation (DDES) by Menter et al. [18] in 2004 for the SST $-k-\omega$ model and more generally in 2006 by Travin et al. [33]. In channel simulations with massivly refined grids near the walls (LES-like grid) the standard DES97 shows two stacked logarithmic layers, which causes a significant and unphysical reduction of the friction coefficient. This effect is called 'log layer missmatch' (LLM). The DDES modification avoids the the activation of the LES mode inside the boundary layer, it 'delays' the switching to the LES mode into well seperated regions, far from walls. Travin et al. $[33,31]$ publicated in 2006 a modification of the DDES approach, that has shown promising results for fully-developed turbulent channel flows. This variant is known as 
'improved DDES' (IDDES) and has been implemented and validated at the ISTA SAE and CEASM DDES variants by Mockett [20]. The major advantage over the former DES variants is the possibility to simulate resolved turbulent boundary layer structures. It is therefore used in the present study.

The IDDES approach uses a more complex formulation for evaluating the grid filter $\Delta$ and for the blending of the grid filter with the RANS turbulent length scale $\left(L_{R A N S}\right)$. The grid filter depends additionally on the wall normal distance $d_{w}$ and the height of the cell in wall normal direction $h_{w n}$ :

$$
\Delta=\min \left(\max \left[C_{w} d_{w}, C_{w} h_{\max }, h_{w n}\right], h_{\max }\right) \quad \text { and } h_{\max }=\max \left(\Delta_{x}, \Delta_{y}, \Delta_{z}\right)
$$

Here $C_{w}$ is a model constant. The blending is done by a so called 'hybrid function' $f_{h y b}$, that includes the functionality of former developed DDES $\left(f_{d}\right)$ with the shield function $\Psi$ and formulates the modified length scale $\tilde{l}$ as follows:

$$
\tilde{l}=f_{\text {hyb }}\left(1+f_{\text {restore }}\right) L_{R A N S}+\left(1-f_{\text {hyb }}\right) L_{\text {LES }}
$$

with

$$
L_{L E S}=C_{D E S} \Psi \Delta \quad \text { and } \quad f_{h y b}=\max \left\{\left(1-f_{d}\right), f_{\text {step }}\right\}
$$

The functions $f_{d}, f_{\text {restore }}, f_{\text {step }}$ and $\Psi$ are defined in a complex manner by analysis of the local boundary layer flow paramters. The complete description of the IDDES approach is presented in $[33,31]$.

\section{IDDES of a fully turbulent periodic channel flow}

The advantage of this IDDES approach is demonstrated here for a turbulent, 3D, periodic channel flow at $R e_{\tau}=2000$. The standard DES of this configuration both on coarse and fine grids always tends to a simple RANS solution without resolving turbulence. If one forces the solution to resolve the turbulence, the DES shows a typical log-layer mismatch (LLM) with an incorrect prediction of the friction coefficient. The IDDES reproduces the correct behavior independent from the grid resolution with resolved turbulence on fine grids. In Fig. 3 the results of the EASM-IDDES for $R e_{\tau}=2000$ and $u_{b u l k}=22.4 \mathrm{~m} / \mathrm{s}$ with the channel half height of $H / 2=1.0 \mathrm{~m}$ on different grids are summarized. The basic grid is designed as a LES grid for the Reynolds number $R e_{\tau}=400$, with a wall normal grid size of $y^{+}<0.5$ and a wall tangential resolution in stream wise direction of $\Delta x=\Delta z \cdot 2$ with $\Delta z^{+}<20$. The initial field is composed of the result of a precurser 2D-RANS added with the resolved turbulence of the DIT case (decay of isotropic turbulence). A slice through the domain is shown with the $\mathrm{x}$-component of the velocity on the left side of Fig. 3(a) for three different stream-wise grid resolutions. From top to the bottom, the LES-like grid $(\Delta x=2 \cdot \Delta z)$, the intermediate grid $(\Delta x=8 \cdot \Delta z)$ and a RANS-type grid with high aspect ratio cells $(\Delta x=32 \cdot \Delta z)$ are shown. The differences are obvious. The coarsest grid shows a RANS solution, whereas the finer grids show resolved turbulence in the core of the channel. The blending 


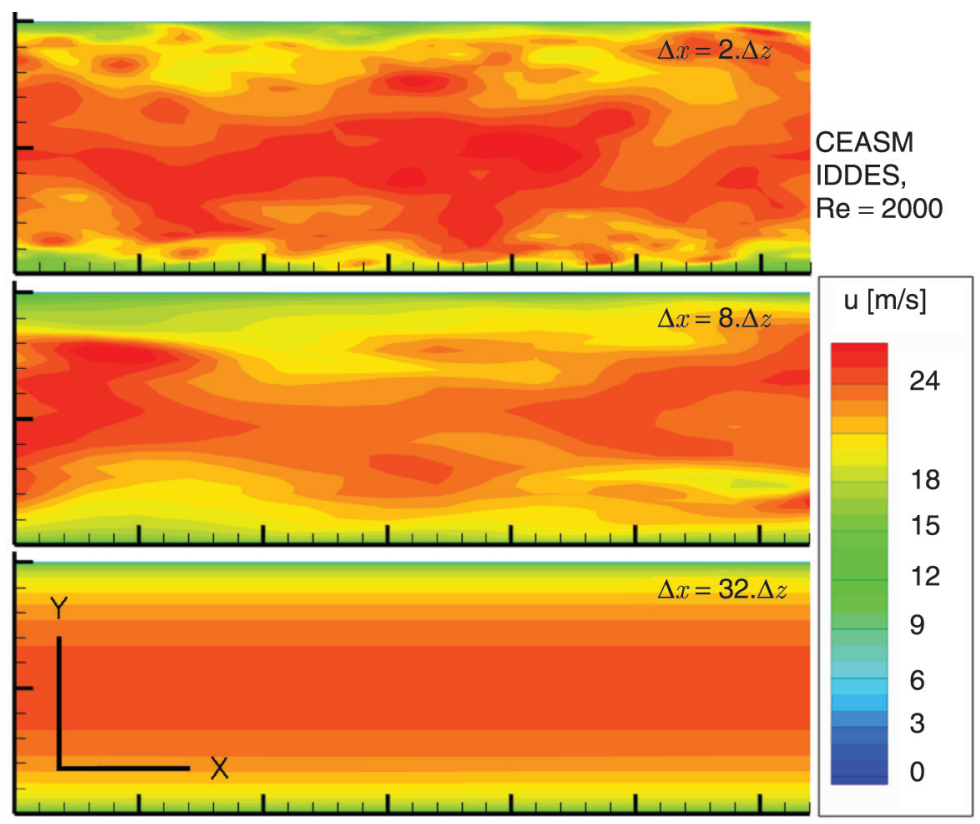

(a) Stream wise 2D cut through channel with u-velocity for three different grids
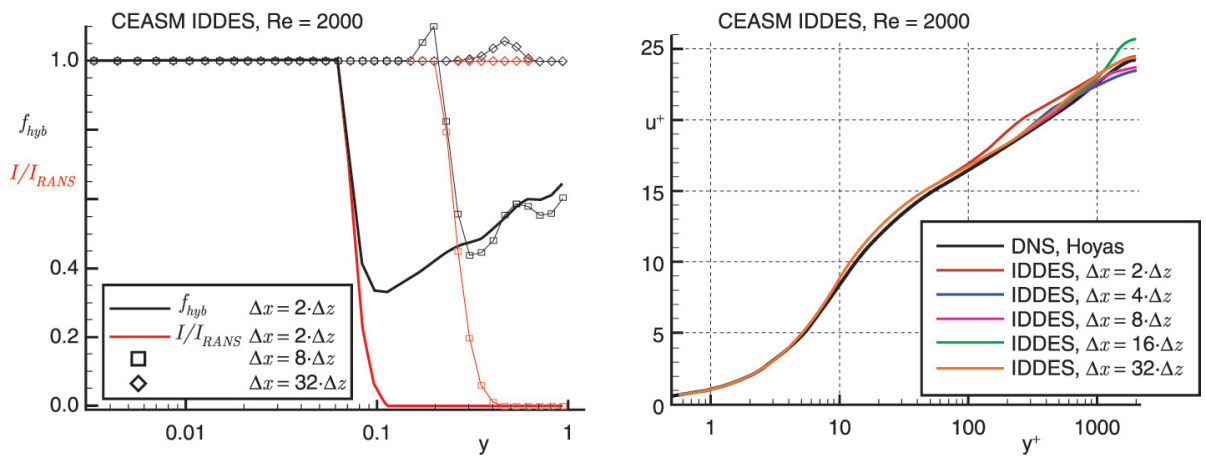

(b) Left:blending function $f_{h y p}$ (red) and IDDES turbulent length scale (black) over the channel height; right: boundary layer-profiles compared to DNS Data from Hoyas [13]

Figure 3: IDDES of turbulent periodic channnel flow at $R e_{\tau}=2000-$ demonstration of wall modeling LES capabilities of the CEASM IDDES on different grids.

between the RANS an the LES mode happens inside the turbulent boundary layer, that is depicted in the left plot of Fig. 3(b). In this plot the blending function $f_{h y b}$ (red color) and the resulting model length scale $\tilde{l}$ (normalized with the RANS length scale $L_{R A N S}$, black color) are shown. For the LES-like grid more than $92 \%$ of the channel is in the 
LES mode, for the intermediate grid approximately $75 \%$ is in the LES mode and the coarse grid simulation is only in RANS mode. The analysis of the boundary layer $u^{+}=f\left(y^{+}\right)$-profiles in Fig. 3(b) rigth shows for all grids very good results compared to the DNS from Hoyas et al. [13]. Therefore the IDDES shows consistent results independent of the near wall grid resolution for the fully turbulent periodic channel flow.

\subsection{FWH}

Based on the work of Lighthill [16] and Ffowcs-Williams and Hawkings [8], the unsteady pressure and velocity fluctuations in the flow field constitute the sources of an inhomogeneous wave equation governing the noise propagation problem. These fluctuating values can be derived from unsteady CFD. The equation used for computing the acoustic far field at different observer positions based on Farassats formulation 1A [6] for penetrable surfaces reads as follows:

$$
\begin{aligned}
4 \pi p^{\prime}(\vec{x}, t) & =\int_{s}\left[\frac{\varrho_{0}\left(\dot{U}_{n}+U_{\dot{r}}\right)}{r\left(1-M_{r}\right)^{2}}\right]_{r e t} d S+\int_{s}\left[\frac{\varrho_{0} U_{n} K}{r^{2}\left(1-M_{r}\right)^{3}}\right]_{r e t} d S \\
& +\frac{1}{a} \int_{s}\left[\frac{\dot{L_{r}}}{r\left(1-M_{r}\right)^{2}}\right]_{r e t} d S+\int_{s}\left[\frac{L_{r}-L_{M}}{r^{2}\left(1-M_{r}\right)^{2}}\right]_{r e t} d S+\frac{1}{a} \int_{s}\left[\frac{L_{r} K}{r^{2}\left(1-M_{r}\right)^{3}}\right]_{r e t} d S
\end{aligned}
$$

with

$$
\begin{aligned}
& U_{n}=\left(1-\frac{\varrho}{\varrho_{0}}\right) v_{n}+\frac{\varrho u_{n}}{\varrho_{0}} \quad K=r \dot{M}_{r}+a M_{r}-a M^{2} \quad M_{r}=\frac{v_{r}}{a} \\
& L_{M}=L_{i} M_{i} \quad L_{r}=\frac{(x-y)_{i}}{r} L_{i} \quad L_{i}=\varrho u_{i}\left(u_{n}-v_{n}\right)+P_{i n} \\
& P_{i n}=\left(p-p_{0}\right) n_{i} \quad \mid \tau_{i j} \text { neglected } \quad r=|\vec{x}-\vec{y}| \quad p^{\prime}=a^{2} \varrho^{\prime}
\end{aligned}
$$

where $[\cdot]_{\text {ret }}$ denotes quantities that have to be evaluated at retarded time $\tau=t-r / a$. In this equation, all terms on the right hand side represent sources located on the surface, the term representing the volume sources (Lighthill term) is neglected. In reference [10], it is shown on a rod-airfoil test case that for low Mach number flows such as the present one, this assumption is justified in cases: either the integration surface coincides with the solid boundaries or it surrounds all the perturbations generated by the flow. The program C3Noise used for acoustic prediction is an in-house developed code and has been validated by Eschricht et al. [27, 29] for configurations of rigid and penetrable surfaces.

\subsection{Numerical setup and grid}

The flow conditions used for the compressible simulation are set according to the experiment. The mean inflow velocity is $U_{i n}=70.204 \mathrm{~m} / \mathrm{s}$ at angle of attack of $\alpha=7^{\circ}$. This inflow angle is quite different with respect to the experiment $\left(15^{\circ}\right)$ due to fact that for the CFD a homogeneous inflow field is used instead of the open jet configuration in 

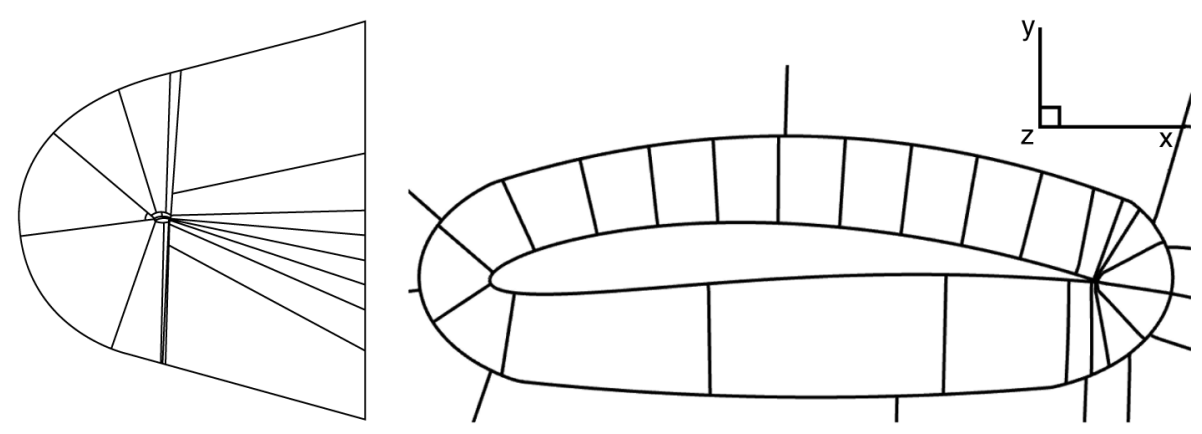

Figure 4: Overview of block structured grid for the NACA 5510: left - whole domain; right - near airfoil.

the experiment. The angle is evaluated from precursor 2D RANS simulations looking for the best fit of the $c_{p}$-distribution compared to the experiment. Further inflow conditions are $p_{i n}=98667 \mathrm{~Pa}, T_{i n}=292.06 \mathrm{~K}, \varrho_{i n}=1.1702 \mathrm{~kg} / \mathrm{m}^{3}$ with a turbulence intensity of $\mathrm{Tu}=0.7 \%$. The molecular viscosity for air is $v=1.4613 \cdot 10^{-5} \mathrm{~m}^{2} / \mathrm{s}$. The corresponding chord length $(c=0.2 \mathrm{~m})$ based Reynolds number is about $R e_{c}=960.000$. An adiabatic low-Reynolds no-slip condition is imposed on the solid boundaries. Non-reflecting boundary conditions from Bogey \& Bailly [2] are imposed on the far field boundaries. The time step used in the aerodynamic simulation is $1.0 \cdot 10^{-6} \mathrm{~s}$. A forcing technique similar to one used for the channel test case in section 3.2 is applied to initial steps of the present simulation. At the first time step the velocity fluctuations of the DIT test case are added to the flow field solution at the immediate vicinity of the airfoil. After all spurious noise caused by this forcing has disappeared from the domain the statistics for the simulation is started. The grid consists of 5.3 million cells in 40 blocks and extends approximately $26 c$ in stream-wise direction, $20 c$ in the cross-stream direction at the airfoil position $(29 c$ at the outlet) and $0.05 c$ in span-wise direction $(1 \mathrm{~cm})$. The topology of the block-structured grid is shown in Fig. 4. It is composed of an O-grid around the airfoil and a $\mathrm{C}$-grid elsewhere. The grid on a slice through the domain near the airfoil together with the zoomed detail of the leading edge and the detailed view of the trailing edge is depicted in Fig. 5 and Fig. 6, respectivily. On the suction side a (coarse) LES-like grid is built with a stream-wise grid size of $\Delta z=0.5 \mathrm{~mm}(0.0025 c$ chord length), whereas on the pressure side the stream-wise grid size is four times bigger $(\Delta z=2.0 \mathrm{~mm})$. Towards the leading and even more towards the trailing edge the mesh is smoothly refined. This yields 922 cells in the circumferential direction, whereof approximately 450 are located on the suction side and 120 on the pressure side. The trailing edge height is $0.4 \mathrm{~mm}$ and rounded at the edges to avoid massivly sheared cells in the O-grid (see Fig. 6). Many cells are clustered near the TE to get nearly cubic cells in the surrounding area. The $3 \mathrm{D}$ grid is generated by reproducing the two dimensional grid 40 times in the span-wise direction. The cell size in span-wise direction is $\Delta z=0.25 \mathrm{~mm}=0.00125 c=1 / 2 \cdot \Delta x_{\text {suction side }}$. 


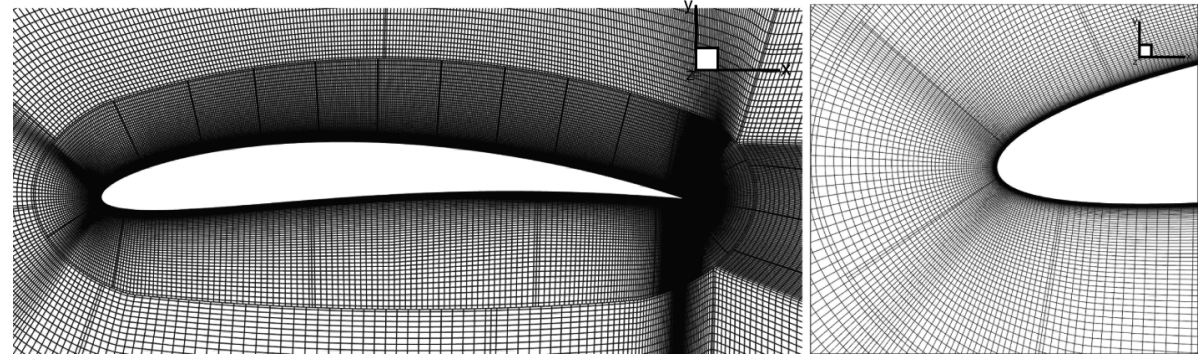

Figure 5: $\quad$ Grid slice around NACA 5510 with detail near leaging edge.

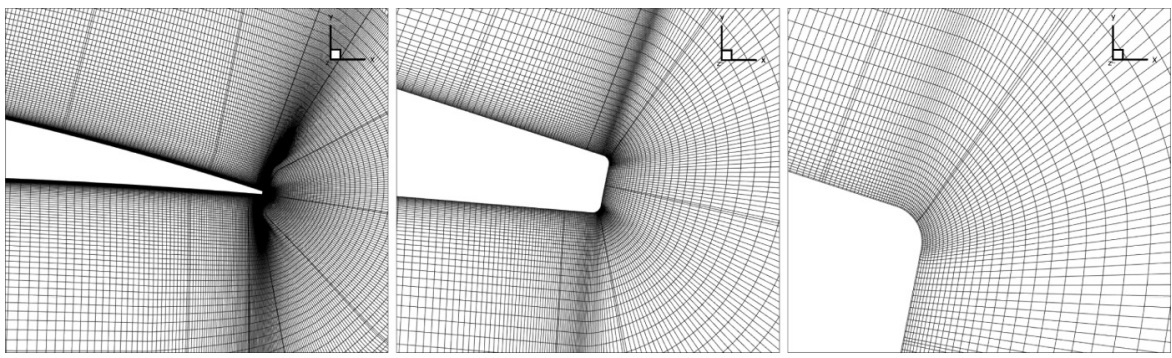

Figure 6: Grid detail near trailing edge of NACA 5510 airfoil (three zoom levels), trailing edge height is $\approx 0.4 \mathrm{~mm}$.

On the complete airfoil the first cell size normal to the wall is in turbulent units $y^{+}<0.4$ with a peak value of $y^{+} \approx 0.65$ at the stagnation point (see Fig. 7). The corresponding stream- and span-wise grid resolution are around $\Delta x^{+} \approx 100$ (black curve without symbols) and $\Delta z^{+} \approx 50$ (red curve without symbols) for the suction side as depicted in Fig. 7 right. The pressure side shows a quite coarser stream-wise resolution with $\Delta x^{+}$up to values of 270 , but small values for the span wise turbulent grid size of $20<$ $\Delta z^{+}<40$ (black and red curve with symbols). Hence we have a relative coarse LES-like grid on the suction side and a fine RANS-like grid on the pressure side, a quite challenging task for a LES wall model.

\section{AERODYNAMICS}

The IDDES simulation of the flow around the NACA 5510 airfoil shows a resolved turbulent boundary layer on approximately $90 \%$ of the suction side. On the other hand, the pressure side remains in RANS mode. In Fig. 8, a snapshot of the resolved vortex structures is shown by isosurface of the $\lambda_{2}$-criterion coloured by the velocity magnitude. The domain is mirrored on the front- and back-side in spanwise direction. On the midspan plane, the time derivative of the pressure is also plotted in shades of grey. This provides a view of the aeroacoustic source regions and the wave propagation 

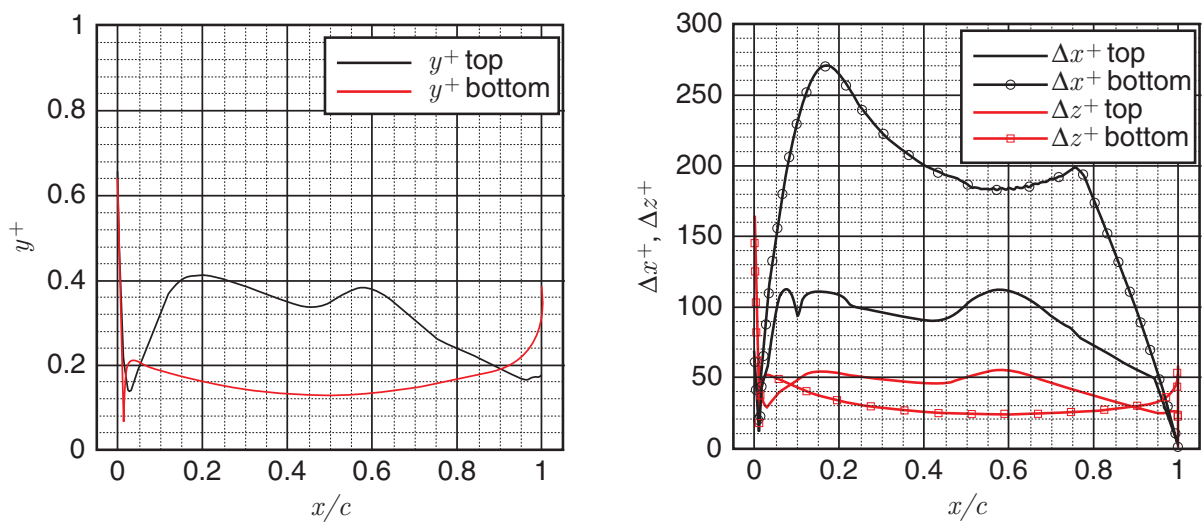

Figure 7: Non dimensional grid spacing: left $-y^{+}$(normal to wall); right $-\Delta x^{+}$ and $\Delta z^{+}$(stream wise and span wise direction); averaged over 8000 time steps.

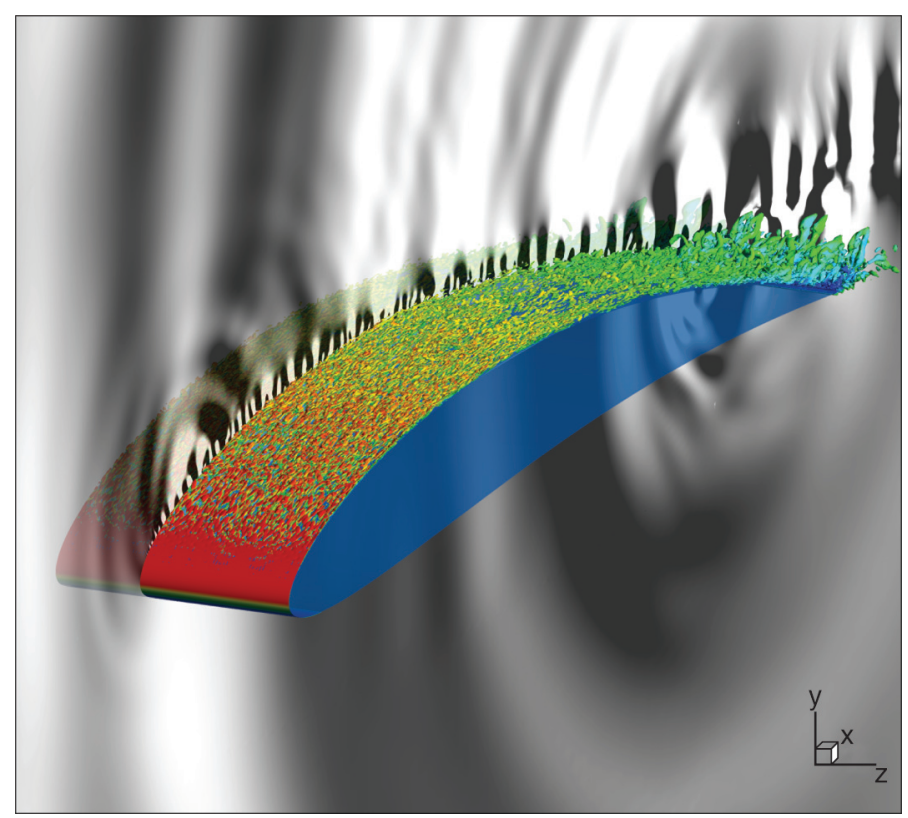

Figure 8: Visualization of vortex structures by a $\lambda_{2}$-isosurface coloured with the velocity magnitude (domain is mirrored in span-wise direction at front and back side), the time derivative of the pressure is given on a 2D cut in shades of gray to visualize the waves propagating away from the airfoil. 


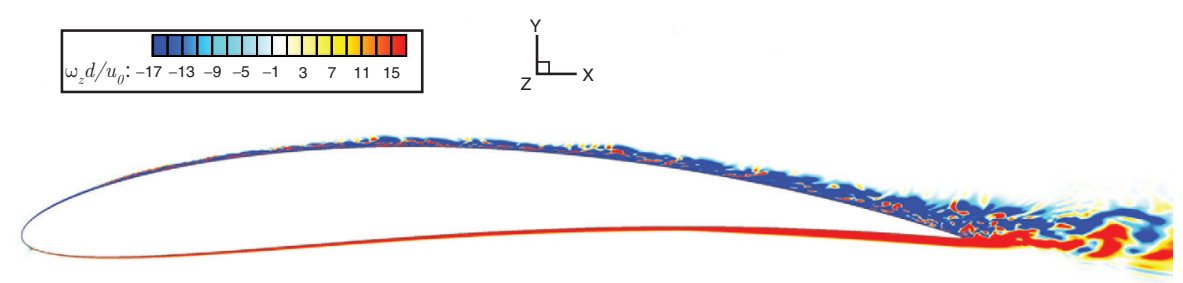

Figure 9: Normalized vorticity $\omega_{z} c / u$ on a mid-span plane.

in the near field of the airfoil as computed by the compressible CFD-solver. On the suction side, the flow is laminar near the stagnation point. At $10 \%$ chord length the massivly sheared viscous flow becomes unstable at the outer edge of the boundary layer and immediately breaks up into small structures due to the flow deceleration. The velocity magnitude is still over $110 \mathrm{~m} / \mathrm{s}\left(\approx 1.6 \times U_{\text {in }}\right.$, red color $)$ in this transitional region. The resolved, turbulent boundary-layer structures travel downstream with a decreased convection velocity into the direction of the trailing edge. The mean flow is generally attached near the trailing edge but shows some events with recirculating flow. Therefore, the size of the stuctures grows massively at the TE.

There are no resolved boundary layer structures on the pressure side in the simulation - no structures are visible by the $\lambda_{2}$-criterion. The major acoustic source region is located near trailing edge. A secondary source region can be observed near leading edge, shortly after the transition due to the accelerated vortical structures. The frequency of this pressure fluctuation is very high $(\approx 20-40 \mathrm{kHz})$ with sound pressure levels more than $20 \mathrm{~dB}$ lower than the TE noise, which is not surprising since there is no geometrical singularity nearby. The normalized z-component of the vorticity $\omega_{z} c / u$ is depicted in Fig. 9. The difference between the boundary layer on the suction and pressure side is obvious: On the pressure side the boundary layer (BL) is in RANSmode, visible by the highly positive and homogeneous values of $\omega_{z} c / u$ (red color). At $75 \%$ chord lenght the transition to turbulence can be recognized by the growing of the BL thickness. There is a similar thin homogeneous viscous layer in RANS mode on the suction side on the first $10 \%$ of the profile, but with negative levels for $\omega_{z} c / u$. After that point, one can observe mixed areas with positve and negative values in the BL, that can happen only in resolved flows. To determine the blending position between the RANSand LES-mode the blending function $f_{h y b}$ is shown in Fig. 10 in two different plots. The value of $f_{h y b}$ is one in the full RANS-mode and zero in the LES-mode. The upper picture of Fig. 10 shows the same $\lambda_{2}$-isosurface as Fig. 8 now coloured with the blending function. Here the vortical structures in the turbulent boundary are in the LESmode, clearly visible by the red color $\left(f_{h y b}=0\right)$, but one can still recognize the thin, blue area near the airfoil - the viscous layer is in RANS-mode on the suction side. Therefore, the blending occurs inside the boundary layer. In Fig. 10 bottom $f_{\text {hyb }}$ is dipicted on a mid-span plane, but with reversed color scale with respect to the former plot; red color 


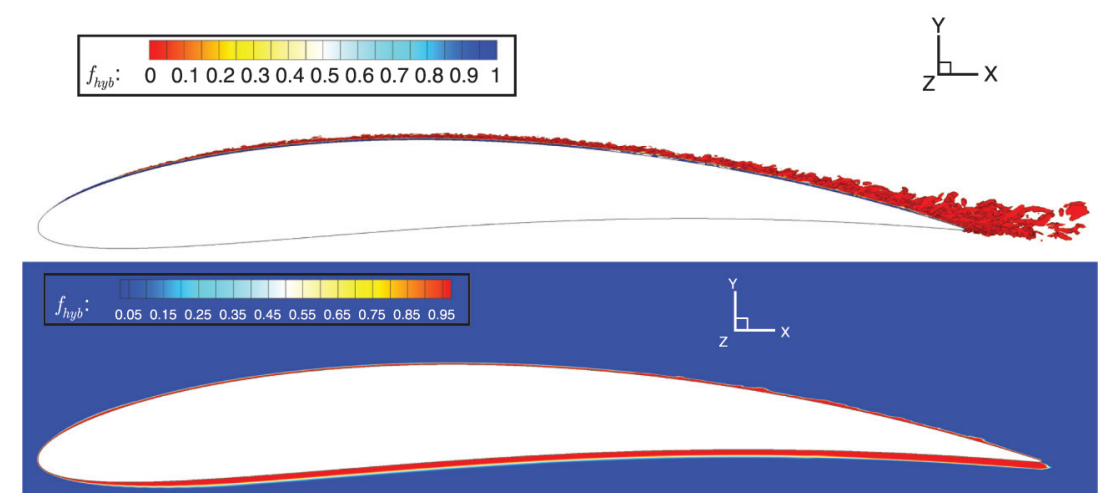

Figure 10: Analysis of IDDES blending parameter $f_{h y b}$; top: $\lambda_{2}$ iso surface colored with $f_{h y b}$ (red - LES mode, blue - RANS mode), bottom: $f_{h y b}$ on a midspan plane (red - RANS mode, blue - LES mode).

is now the RANS-mode $\left(f_{h y b}=1\right)$. The blending on the pressure side occurs outside the boundary layer. Again, the very thin area near the airfoil with the RANS-mode is visible on the suction side, but compared to the top plot of Fig. 10 it appears that the total thickness of the boundary layer is much larger. The mean flow around the airfoil is compared to PIV measurements in Fig. 11. Both, $u_{\text {mean }}$ and $v_{\text {mean }}$ are in a fair agreement with the experiment, but velocities are overpredicted up to $9 \mathrm{~m} / \mathrm{s}$ on the suction side by the simulation. This is due to the different setups in experiment and simulation, a open jet configuration versus the homogeneous mean flow field, respectively. Accordingly, differences can be observed in the pressure coefficient $c_{p}$ on the suction side, which is given in Fig. 15. Indeed, the maximum suction is higher in the simulation which explains the strong acceleration.

The detailed analysis of the flow field around the airfoil is shown in Fig. 12. The comparison with hot wire anemometry (HWA) is carried out near the TE at $x / c=0.95$ on the suction side (left plot), on the pressure side (center plot) and in the wake of the airfoil at $x / c=1.05$ (right plot). The upper row shows the time-averaged velocity magitude and the bottom row the RMS-values of the velocity components $u_{\text {rms }}$ and $v_{r m s}$. All values are normalized with the local outer velocity magnitude at a distance of approximately $d=150 \mathrm{~mm}=0.75 \mathrm{c}$ in wall normal direction. The mean profile shows a good agreement at $95 \%$ chord on the suction side (Fig. 12 left). But the boundary layer thickness is underpredicted by the simulation at this posistion. The $u_{\mathrm{rms}}$ and $v_{r m s}$ profiles are narrower, but the maximum levels are overpredicted. The simulation shows at $99 \%$ chord similar profiles and levels compared to the experiment at 95\%. The RMS-levels for the simulation drop down to zero (RANS region) towards the farfield, whereas the experiment shows higher levels due to the jet shear layers. A behaviour similar to that on the suction side can be observed in the wake of the airfoil at $x / c=1.05$ in the right hand side of Fig. 12. It can be noticed that the predicted boundary shear layers are 

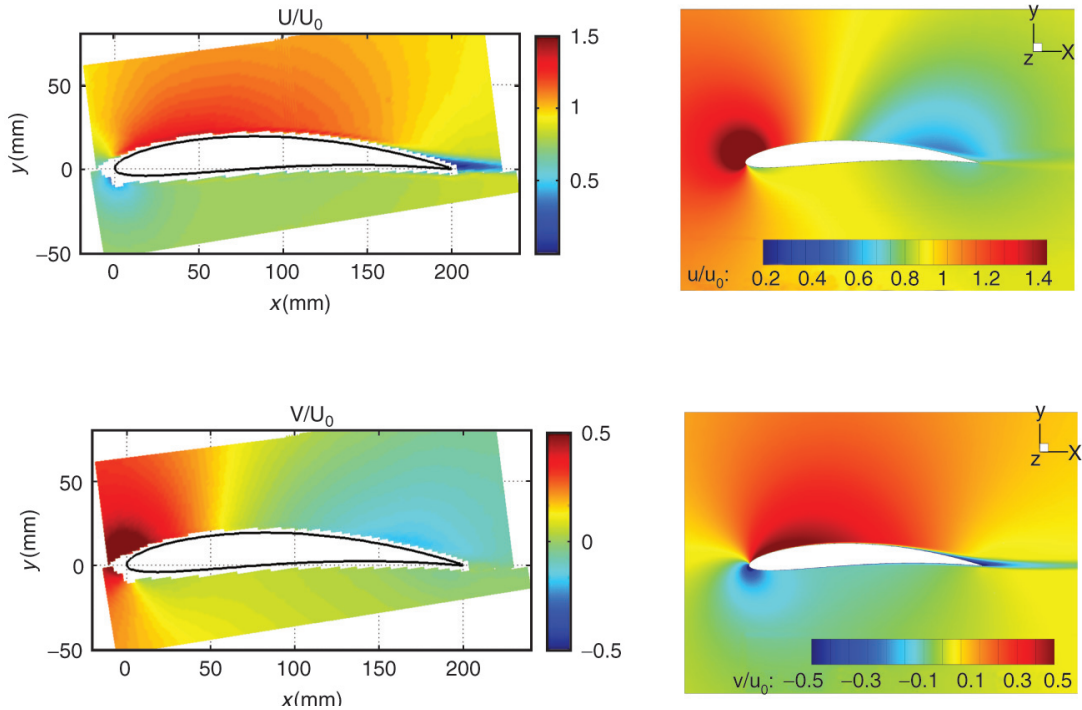

Figure 11: Comparison of PIV (left) and IDDES (right) of the averaged velocity $\mathrm{u}$ - and v-component around the airfoil; top row - u-velocity, bottom row v-velocity.

smaller, but with higher RMS-values. The boundary layer of the pressure side is much smaller near the TE than on the suction side, which is clearly visible in the wake (right plot of Fig. 12) and in the center plot of Fig. 12. In Fig. 13, the boundary layer profiles along the airfoil are depicted for the suction (left) and the pressure side (right). This mean profiles were obtained during the last 37000 time steps $(T=0.037 \mathrm{~s})$. The profiles shown, are normalized by the wall-parallel velocity at a distance $d / c=0.125$ - the normalization velocities for every position are summarized on the top the picture (red numbers). At $10 \%$ chord the maximum outer velocity is about $76 \%$ higher than the free stream velocity. For the suction side the wall-parallel velocity component profiles $u_{\| \mid}$show a fast increasing boundary layer thickness downstream of $50 \%$ chord $(x / c=0.5)$, due to the strong adverse pressure gradient on the airfoil. Downstream of $90 \%$ chord the flow tends to be close to seperation, but it is still attached $\left(\frac{\partial u}{\partial y}\right.$ positive $)$. On the pressure side the boundary layer thickness is smaller and shows between the stagnation point and more than $50 \%$ chord a fully viscous behaviour. After that point transiton to turbulence can be observed. The maximum velocity on the pressure side is less than the freestream velocity $\left(u_{\|}^{\max } / u_{0}=0.94\right.$ at $\left.x / c=0.9\right)$. Fig. 14 depicts some selected boundary layer profiles in a logaritmic scale for the suction side (left plot) and the pressure side (right plot). The non-dimensional $u^{+}=f\left(y^{+}\right)$profiles show a detailed view of the blending behaviour inside the turbulent boundary layer. The symbols flag the position of $f_{\text {hyb }}=$ 0.5 . On the suction side for $10 \%$ chord one can see a typical viscous boundary layer 

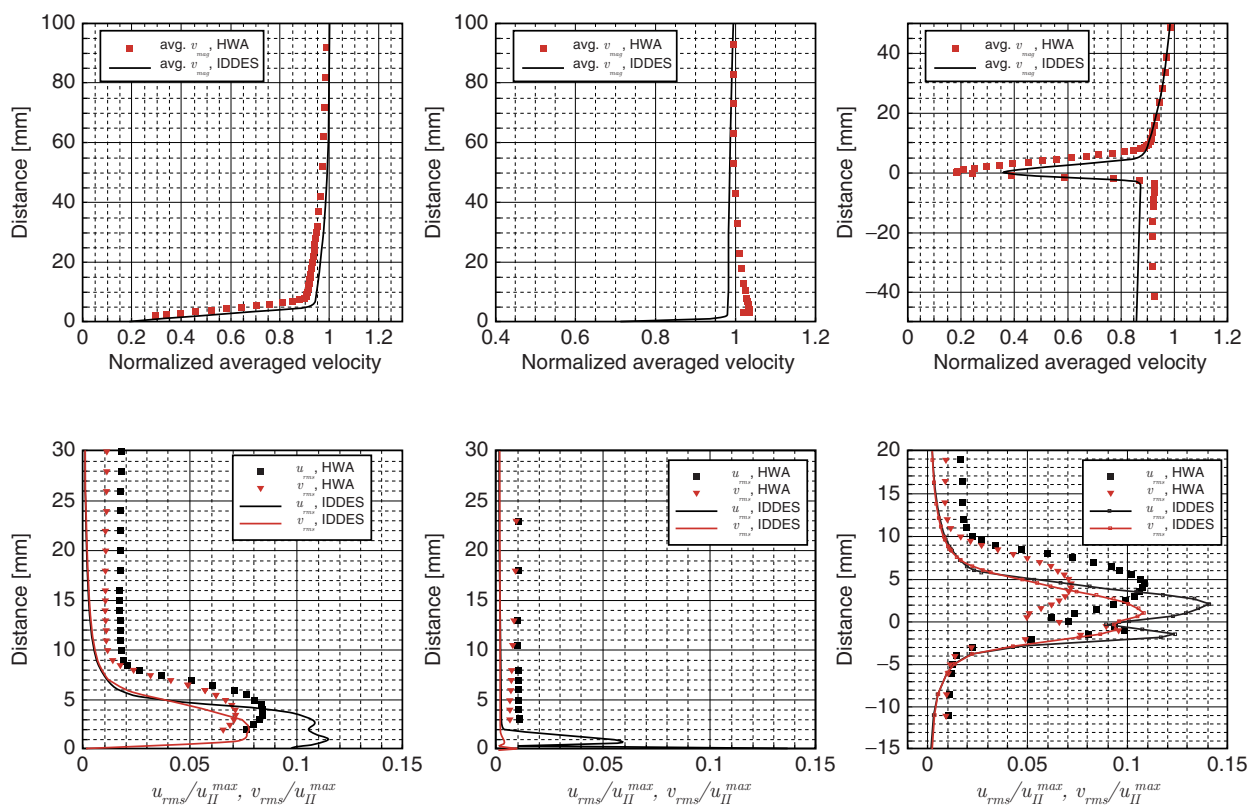

Figure 12: Comparison of normalized averaged velocity and RMS-values of velocity components to HWA measurements near TE $(x / c=0.95)$ on suction side (left) and pressure side (middle) and in the wake at $x / c=1.05$ (right); top row averaged $v_{m a g}$ and bottom row $u_{r m s}, v_{r m s}$, (symbols - HWA, lines - IDDES), normalizition with outer velocity magnitude $u_{\|}^{\max }$.

with blending outside the boundary layer (orange curve). At 25\% (black) and 50\% chord (green) the typical combined viscous and logarithmic laws of the wall can be recognized in the velocity profiles. The blending to the LES-mode occurs inside of the boundary layer at approximately $y^{+} \approx 60$. At $80 \%$ (brown) and especially $97.5 \%$ chord (blue) strong degenerated profiles are found, due to the strong adverse pressure gradient. At the last position the blending occurs around $y^{+} \approx 18$ (see blue curve). The pressure side shows a completely different behaviour. At $10 \%$ (orange), $25 \%$ (black) and $75 \%$ chord (brown curve) the profiles have the typical shape of a viscous boundary layer and the blending to LES occurs outside of the BL. Near the trailing edge at 97.5\% (blue curve) and $100 \%$ chord (green curve) the blending takes place in the logaritmic layer and tends to move into the viscous boundary layer. Only for these two profiles, the blending function is nearly constant $\left(f_{h y b}=0.5\right)$ from the marked positions (blue and green square) to the outer part of the boundary layer. Therefore it is not a real LES-mode in the outer part of the boundary layer at these positions - the resulting turbulent lenght scale in the model is only slightly decreased due to the constant blending of $f_{\text {hyb }}=0.5$. The last part of this section is related to statistics of the force coefficients and wall 

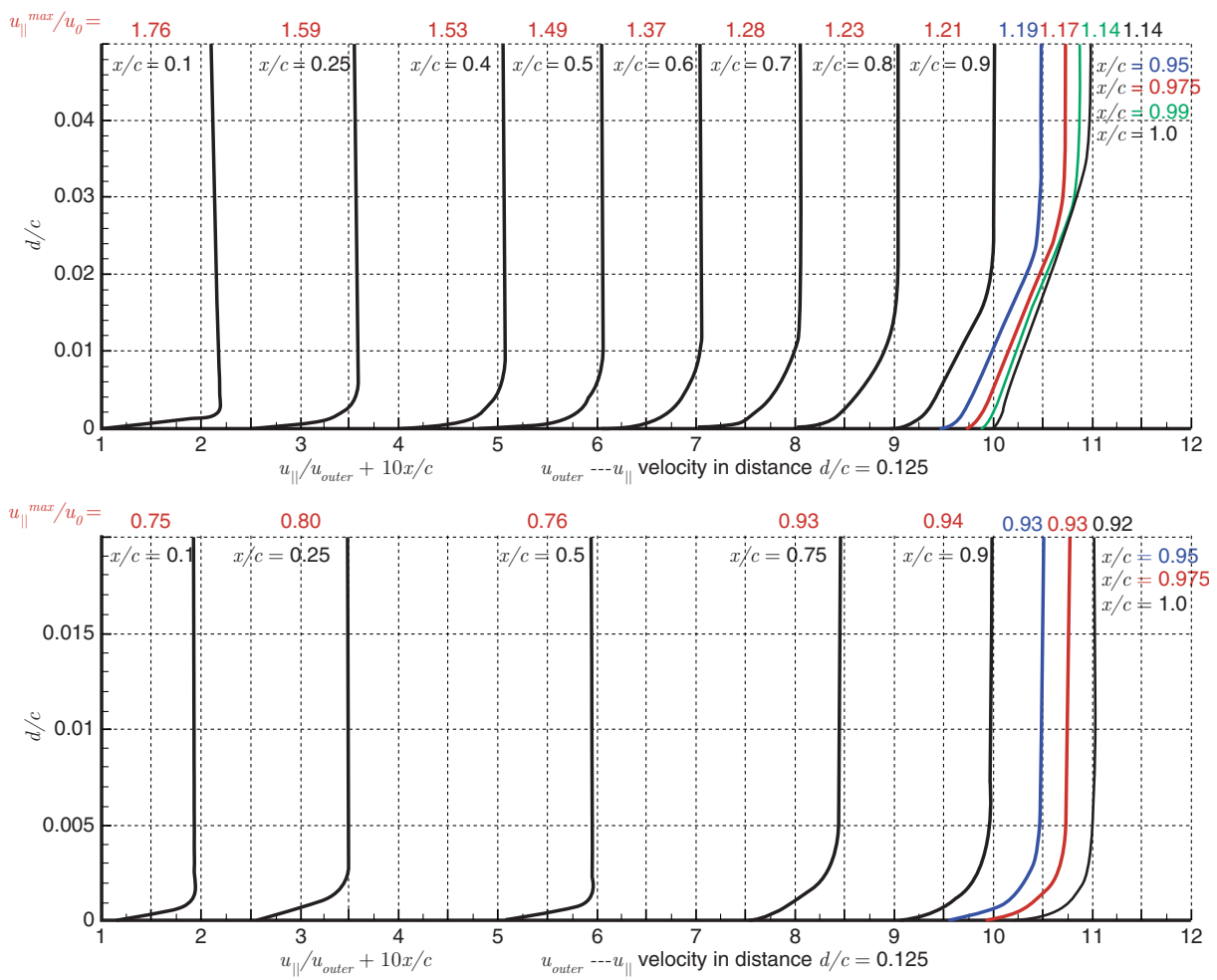

Figure 13: Boundary layer profiles $u_{\|}$for different chord-wise positions normalized with outer velocity $\left(u_{\|}^{\max }\right)$; top - suction side, bottom - pressure side, statistic based on 37000 time steps $(0.037 \mathrm{~s})$.

pressure spectral analysis including spanwise coherence determination. In Fig. 15 the averaged pressure coefficient $c_{p}$ on the airfoil of the simualtion is compared to the experimental data. Whereas the pressure side shows a good aggreement, the differences on the suction side are obvious. Again this is due to the different setups in experiment and simulation, an open jet configuration and the homogeneous mean flow field, respectively. As mentioned above, velocities are higher in the simulation on the suction side. On the left plot of Fig. 17 the time history of the lift $c_{L}$, drag $c_{D}$ and the side coefficient $c_{S}$ is depicted whereas the associated Power Spectral Density analysis is shown on the right plot. The lift has a mean value of about $c_{L}^{\text {mean }} \approx 1.347$ with fluctuation of about $\Delta c_{L}= \pm 0.01$. The drag fluctuations are about one order of magnitude smaller $\left(c_{D}^{\text {mean }} \approx 0.015\right.$ with $\left.\Delta c_{D}= \pm 0.002\right)$, whereas the side coefficient fluctuates around zero with maximal values of $\Delta c_{S}=2.10^{-5}$. All curves are broadband as illustrated by the spectral analysis in the right plot of Fig. 17. The PSD show broadband spectra with a roll-off at $3 \mathrm{kHz}$ with slight tonal peaks at $420 \mathrm{~Hz}$ and $800 \mathrm{~Hz}$. 

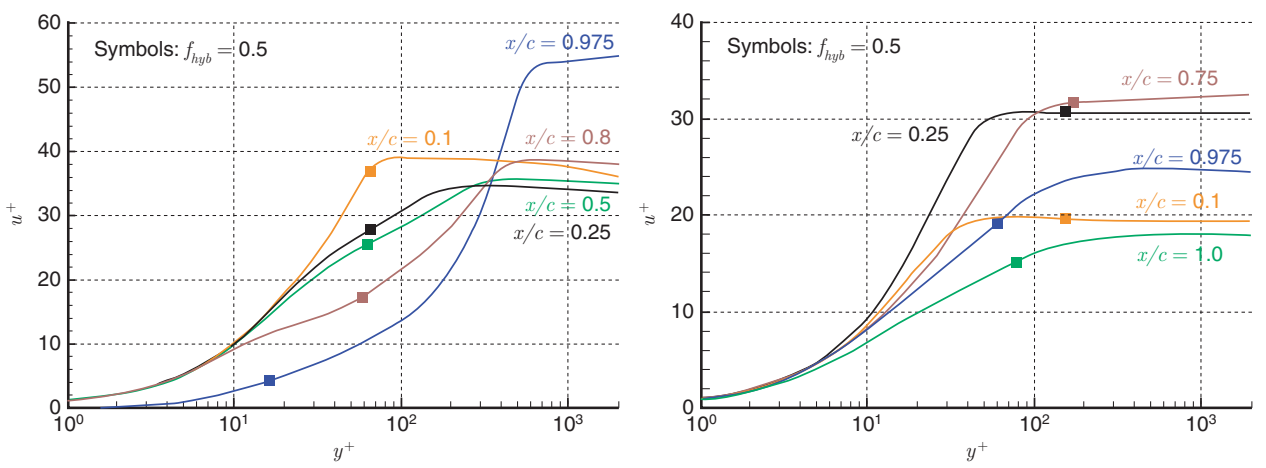

Figure 14: Non dimensionsional boundary layer $u^{+}=f\left(y^{+}\right)$profiles on suction and pressure side, the symbols are to flag the blending between RANS and LES mode by $f_{h y b}=0.5$; left - suction side, right - pressure side, statistic based on 37000 time steps.

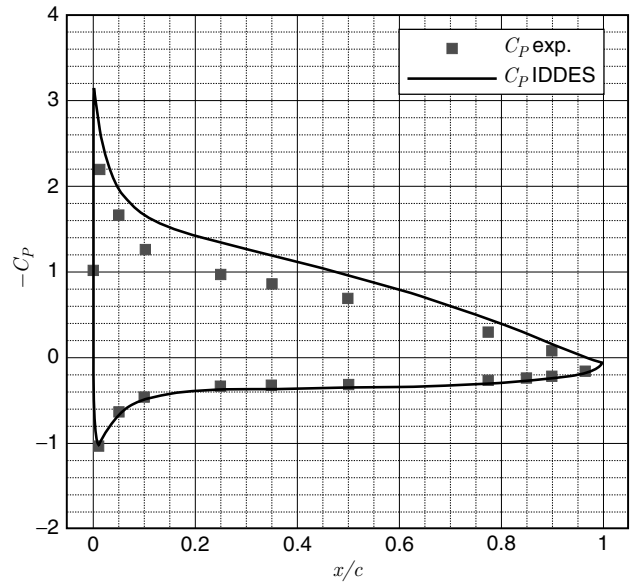

Figure 15: Pressure coefficient $c_{p}$ averaged over 8000 time steps.

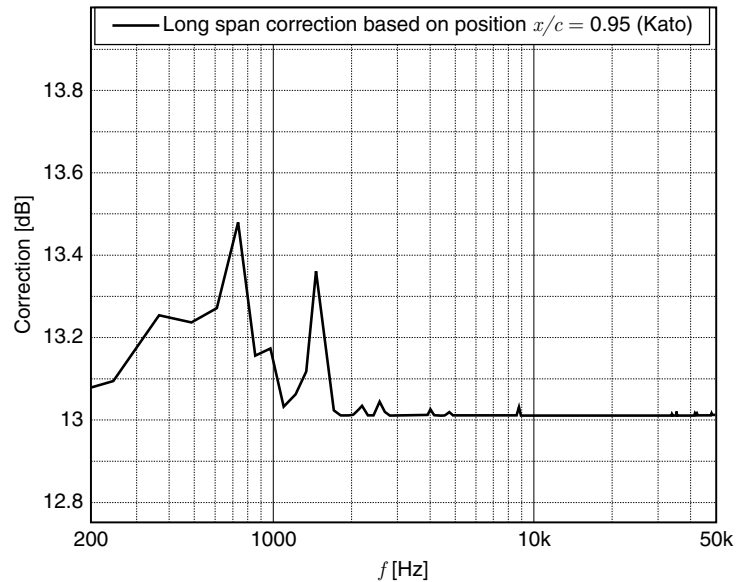

Figure 16: Long span body correction for acoustic based on the coherence lenght analysis. 

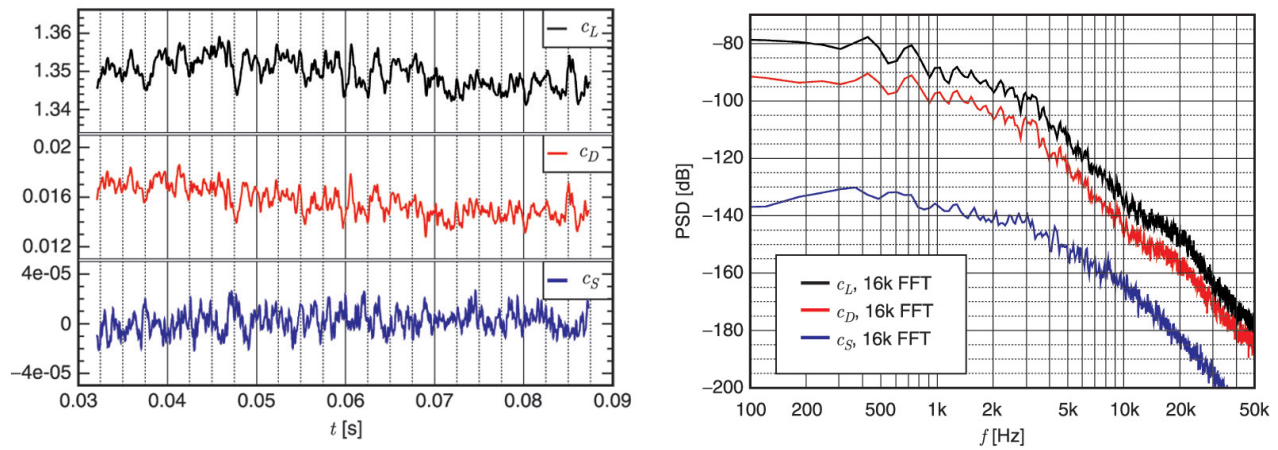

Figure 17: Drag, lift and side coefficient; left: time history, right: power spectral density.

The analysis of the pressure fluctuations near the trailing edge is the link to the acoustic field for this configuration, because the vortical structures generate more noise as they pass nearby the TE than elsewhere. Following this, the on-wall pressure spectra at $95 \%$ chord in Fig. 18 left shows good agreement with the experiment and this lets anticipate similar matching for the acoustic far fields. The predicted levels are about 5-7 dB too high over a wide frequency range, but the spectral shape is very similar, except in the low frequency range for less than $400 \mathrm{~Hz}$. The comparison of the predicted spanwise coherence length to the measured one in Fig. 18 (right plot) shows good agreement from $600 \mathrm{~Hz}$ to $5 \mathrm{kHz}$ (maximum frequency of experimental data). In this range of frequencies the coherence length $\left(L_{c o h}\right)$ is less than $6 \mathrm{~mm}$. At low frequencies the experimental coherence length is very large, which indicates the presence of a completely different flow feature, that can not be reproduced by the simulation. The simulated span of $10 \mathrm{~mm}\left(L_{S}=0.05 \mathrm{c}\right)$ is less than the span of the test configuration $\left(L_{e x p}=1.0 \mathrm{c}\right)$, therefore a scaling correction based on the coherence length analysis has been applied, as suggested by Kato [15]. A new version, combining the three formulas of Kato, of this correction formula between the acoustic and simulated sound pressure levels is chosen here as proposed by Seo et al. [30]. This yields a constant correction of $13 \mathrm{~dB}$ with peaks of $13.4 \mathrm{~dB}$ to $13.5 \mathrm{~dB}$ at $1500 \mathrm{~Hz}$ and $800 \mathrm{~Hz}$, respectively (see Fig. 16). The corresponding coherence length at these frequencies levels is about $L_{c o h} \approx 5 \mathrm{~mm}$, which is approximately the half of the simulated span.

\section{AEROACOUSTICS}

The compressible flow simulation has to cover the near field aeroacoustic radiation and refraction effects. The unsteady flow field data are recorded on control surfaces and fed into a FWH analogy tool, as mentioned in section 3.3. A snapshot of the pressure perturbation $p^{\prime}$ and its time-derivative $\frac{\partial p}{\partial t}$ is shown on the left plot of Fig. 19 in the 

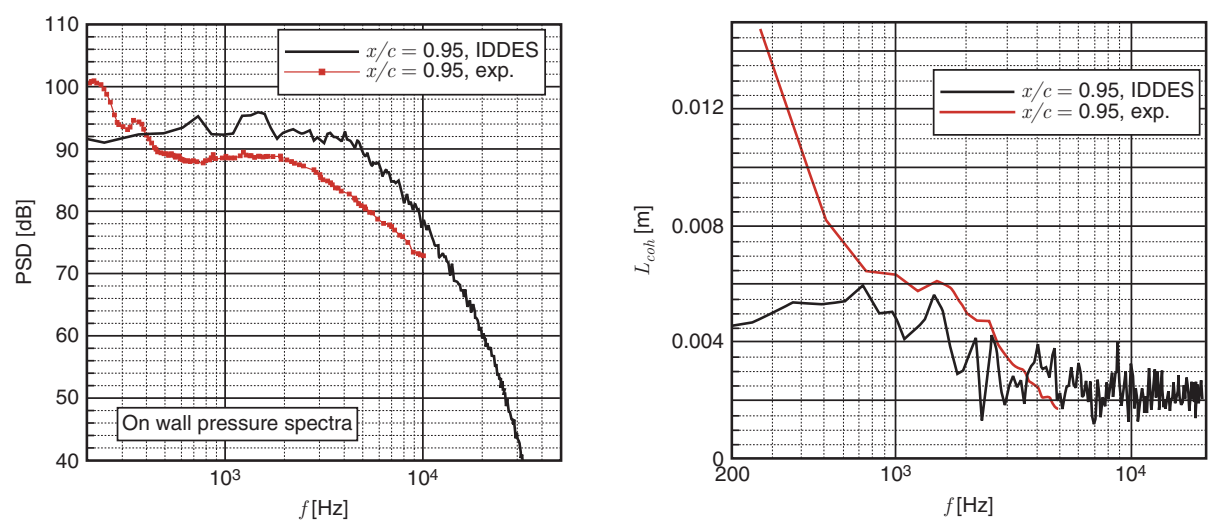

Figure 18: On wall pressure fluctuations near TE $(x / c=0.95)$ : left - PSD spectra at midspan compared to experiment; right - coherence length $L_{c o h}$ in span wise direction.

mid-span plane of the simulated domain. The major acoustic source area near the trailing edge (TE) is clearly visible. The vortical structures in the turbulent boundary layer pass the TE and generate sound. A second sound source is visible in the pressure time-derivative in the right plot of Fig. 19 near the leading edge on the suction side. This sound source is due to the massively accelerated vortex structures near the leading edge. As mentioned in the previous section the frequency of this sound source is very high (more than $10 \mathrm{kHz}$ ) and is highlighted by this kind of post-processing (time derivative) - its SPL-level is $20 \mathrm{~dB}$ to $30 \mathrm{~dB}$ lower than of the TE noise, it is therefore not visible in the pressure perturbation in the left-hand side.

\subsection{Far-field results}

Following the experiment, the far-field sound is computed for 47000 time steps $(\approx 0.047 \mathrm{~s})$ at a distance of $R=1.7 \mathrm{~m}$ from the leading edge of the airfoil. The results from the simulation are rotated to the experimental angle of attack of $15^{\circ}$. The zero angle is aligned with the mean flow direction of the experiment, with positive angles on the suction side (counter clock wise). Measurements are available for angles from $\alpha= \pm 35^{\circ}$ to $\alpha= \pm 145^{\circ}$ with $5^{\circ}$ step. The control surface for the FWH analogy is the airfoil wall surface 's001'. Therefore, only the pressure is recorded and used for the calculation of the far-field sound.

The far-field sound is calculated for observers from $0^{\circ}$ to $360^{\circ}$ with a step of $2^{\circ}$ and compared to the experiment and the semi-analytical trailing edge noise model from Roger and Moreau [23, 22] and Rozenberg et al. [26]. This model is based on Amiet's TE-model for a semi-infinite chord flat plate [1] — it has been extended to finite chord lenght airfoils and 3D oblique pressure gusts. 

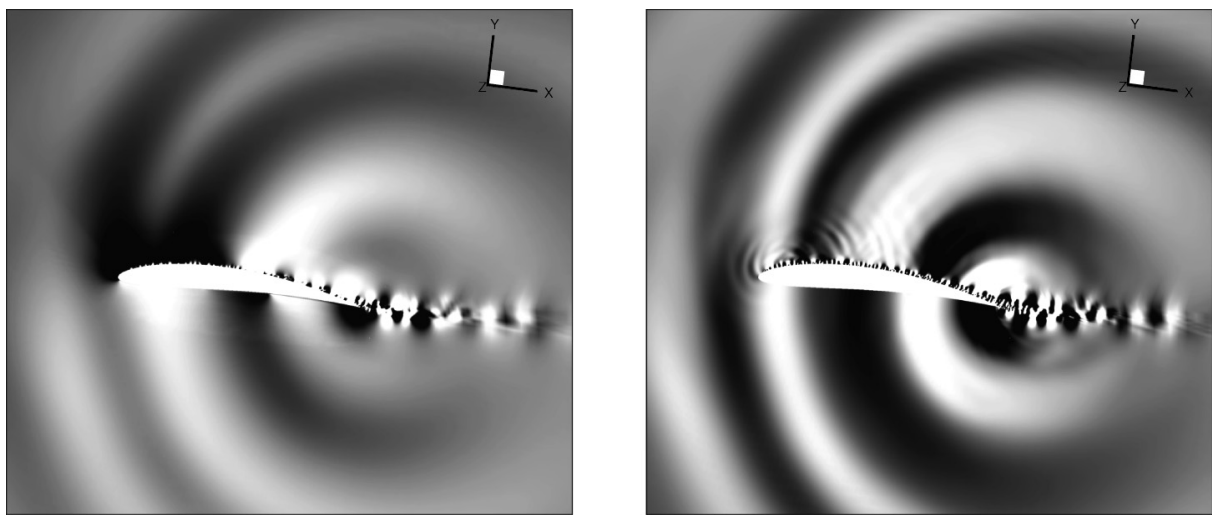

Figure 19: Snapshot of pressure perturbation $p^{\prime}$ (left) and time derivative of pressure $\frac{\partial p}{\partial t}$.

The input of this model can be obtained from the pressure field near the trailing edge far enough upstream to be unperturbed by the trailing edge. In practice, wall pressure statistics (spectrum, span-wise coherence and convection velocity) at approximately $97 \%$ chord are required to predict the farfield spectrum. For cambered airfoils or at significant angles of attack, the BL undergoes a streamwise pressure gradient which also modifies the wall pressure statistics over short distances. This makes the choice of the optimal chordwise position more difficult and results in significant dispersion of the predicted far field spectra. A more recent extension of this model [25] related the wall pressure spectrum at a given chord-wise position to the local boundary layer velocity profile following the ad hoc approach of Goody [9] based on Coles, non-zero pressure gradient BL model [5]. This additional wall pressure modelling allows computing TE noise from RANS computations which don't provide any statistics from wall pressure. In the present case, the far field is computed from the available measured wall pressure statistics. In all plots this model is represented by the acronym TE-model.

The far-field spectra and directivity analysis are plotted on Figs. 20 and 21 : The Power Spectral Density (PSD) is expressed on a dB scale with reference $4 \cdot 10^{-10} \mathrm{~Pa}^{2}$ $\mathrm{Hz}$. The spectra of the simulation are calculated by a FFT with 8192 samples with 50 averaging which yields a frequency resolution of $\Delta f_{\text {sim }} \approx 122 \mathrm{~Hz}$, whereas the experiment uses $\Delta f_{\text {exp }} \approx 7.8 \mathrm{~Hz}$ and the TE-model $\Delta f_{T E \text {-model }}=100 \mathrm{~Hz}$. On subplot 20(a) results from the suction side are plotted whereas subplot 20(b) shows the corresponding pressure side results. In the centre plots of Fig. 20 that correspond to the cross-stream directions, a good agreement between the experimental data (red dots) and the fully numerical (CFD-CAA) prediction (black line) is reached between 1 and $5 \mathrm{kHz}$. Outside of this frequency domain the experiment outranges the computation. At low frequencies, the high experimental values might be explained by installation effects but 

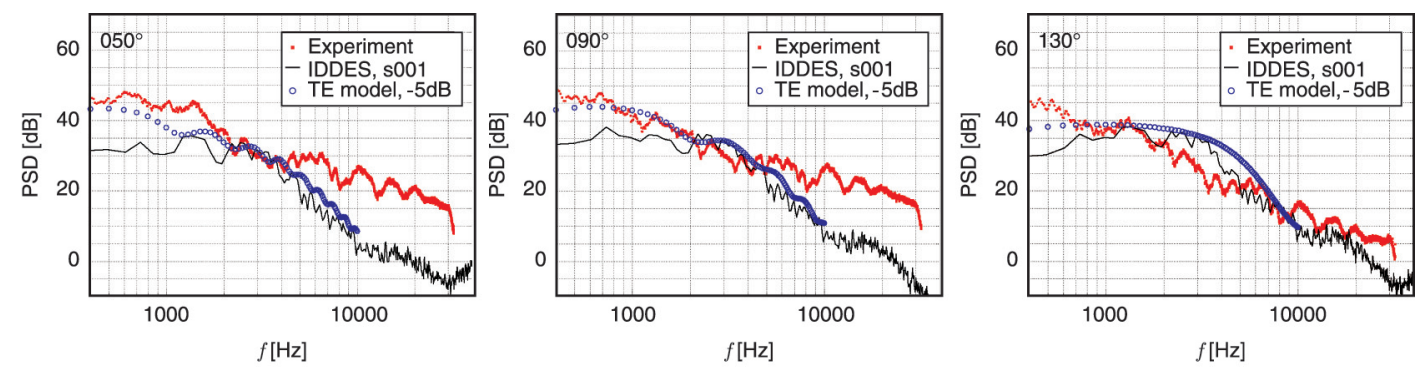

(a) Observers at $\alpha=50^{\circ}, \alpha=90^{\circ}$ and $\alpha=130^{\circ}$
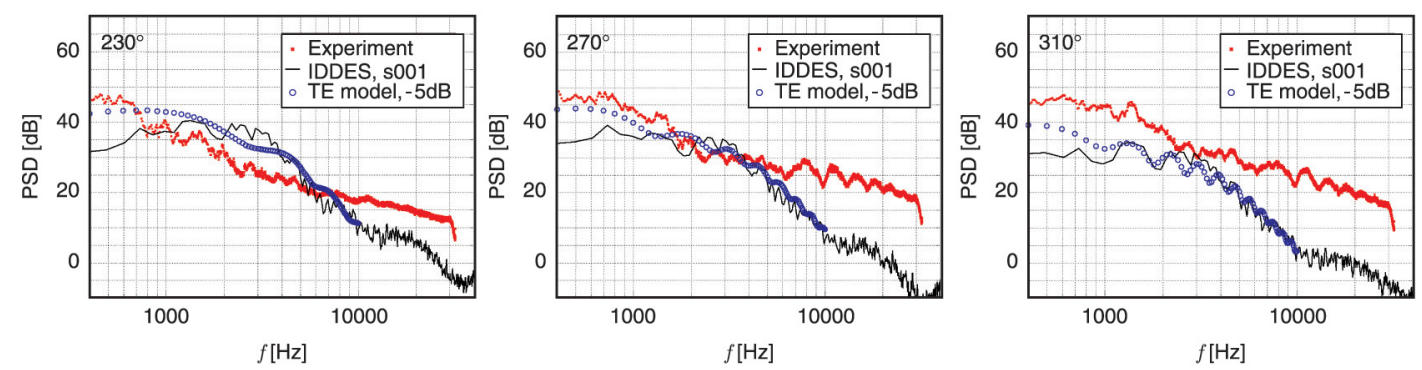

(b) Observers at $\alpha=230^{\circ}, \alpha=270^{\circ}$ and $\alpha=310^{\circ}$

Figure 20: Far-field sound for different observers compared to measurements (red) and TE model from Rozenberg (blue circle).

also by the underestimate of the spanwise coherence obtained from the CFD. At high frequencies, the reason is not clear, but since background noise was found to be significantly lower in the experiment for these frequencies, the discrepancy might be due to errors of the numerical estimate due to the relatively short simulation time. Similar conclusions might be drawn from the left and right plots obtained at low and high observer angles respectively.

As for the TE model, the results are quite surprising: the model fits very well to the CFD-CAA data between 1 or $2 \mathrm{kHz}$ and say, $10 \mathrm{kHz}$ for most observer angles but fits much better with the experimental results at low frequencies (except at $310^{\circ}$ ). Evidence of this is also clear from Fig. 21 where the directivity diagrams obtained from the fully numeric and the TE-model predictions are compared at various frequencies. This comparison also shows the characteristic dipole pattern of a compact airfoil at low frequencies with additional lobes appearing as the frequency increases. For frequencies and angles at which the numerical and the experimental data collapse, the model also gives remarkable results.

From these results, it seems that the CFD-CAA approach clearly underestimates the low frequency part, whereas the model and the CFD-CAA approach collapse the high frequency part of the sound spectra which they both seem to underestimate. These 
differences might be due to the fact that the experimental and numerical flow configurations are quite different and that the far-field estimate is very sensitive to the wall pressure data as can be concluded from a comparison of data sets from literature. Nevertheless, the excellent agreement between the CFD-CAA approach and the TE model approach proves that the fully numeric approach is very consistent. Their quite good fitting with the measured far field gives confidence into both predictions. This implies that the aerodynamic data set is accurate enough to make reliable far field predictions and that the TE noise model can be applied to higher Mach numbers and thicker airfoils than it had been so far. The major restriction in the results can be observed in the low frequency area, due to the short simulation time and the low span-wise extent. Another improvement would be to apply the TE-model directly to the wall pressure field obtained from the simulation in order to evaluate the model against the FWH approach. This would require long CFD time series as well as a larger span-wise dimension of the CFD domain in order to compute more accurately the span-wise coherence.

\section{CONCLUSION}

The novel IDDES approach was successfully applied to the direct simulation of trailing edge noise of an airfoil. The NACA 5510 airfoil at a high angle of attack and a Reynolds number of one million shows a fully attached turbulent boundary layer, whereupon its vortical structures interact with the trailing edge and generate sound.

The IDDES is an extension of the standard hybrid RANS/LES Detached Eddy Simulation method (DES) with the capability to resolve the turbulent boundary layer structures, if fine, LES-like meshes are used in the area of interest. The direct simulation of the trailing edge noise of the NACA 5510 airfoil, using the IDDES method, shows the expected performance. A mesh of approximately 5.3 million cells is used to simulate a span-wise extent of $5 \%$ of the chord. On the suction side a fine mesh is used. On the pressure side a four times coarser mesh is used, because no relevant structures are expected here. The outcome of this is that more than $90 \%$ of the boundary layer on the suction side is in LES mode. On the contrary, the pressure side is fully in RANS mode. The turbulent structures on the suction side are transported to the trailing edge. The detailed analysis of the flow, statistics and spectra near the trailing edge show a good agreement with the experiment. Over a wide range of frequencies the far-field sound results are very close to the theory, that uses the measured on-wall spectra, coherence length and pressure gradient near the TE. The major restriction in the results can be observed in the low frequency area $(\leq 500 \mathrm{~Hz})$.

The IDDES approach is successfully applied to this complex configuration and shows the capability for the simulation of complex, applied cases, e.g turbomachinary flows. The ability to reproduce resonable results on meshes of different fineness is the major advantage of the IDDES. With the use of fine meshes in the area of interests, i.e. wall boundary layer, the user has the possibility to get a direct simulation of the noise generation mechanism, as shown here for the direct simulation of trailing edge noise. On the other hand the use of coarser grids elsewhere can reduce the computational costs in respect to a LES. To conclude, the IDDES should be further investigated, to get a valid basis for the implementation in industrial turbomachinary simulation tools. 


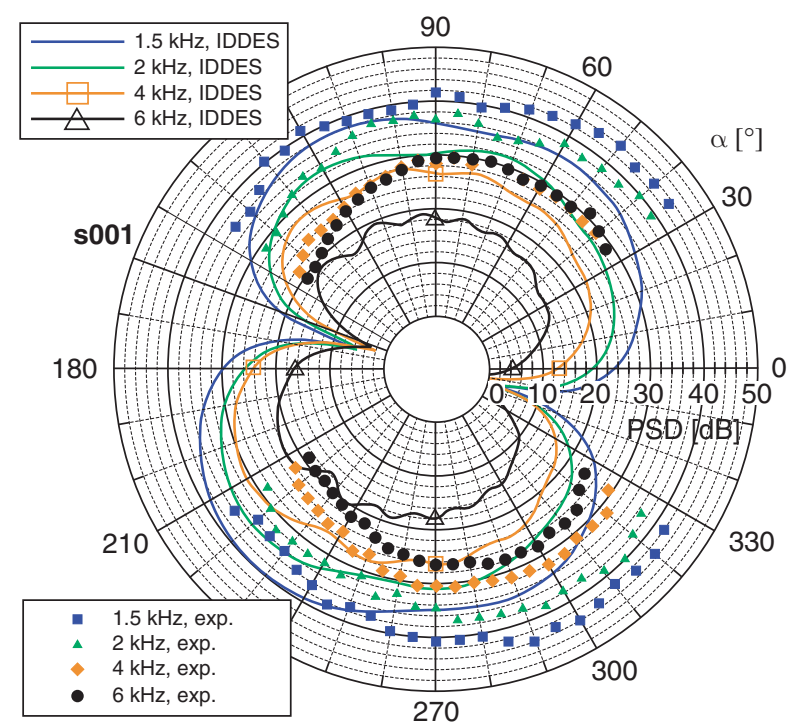

(a) Comparison experiment and IDDES

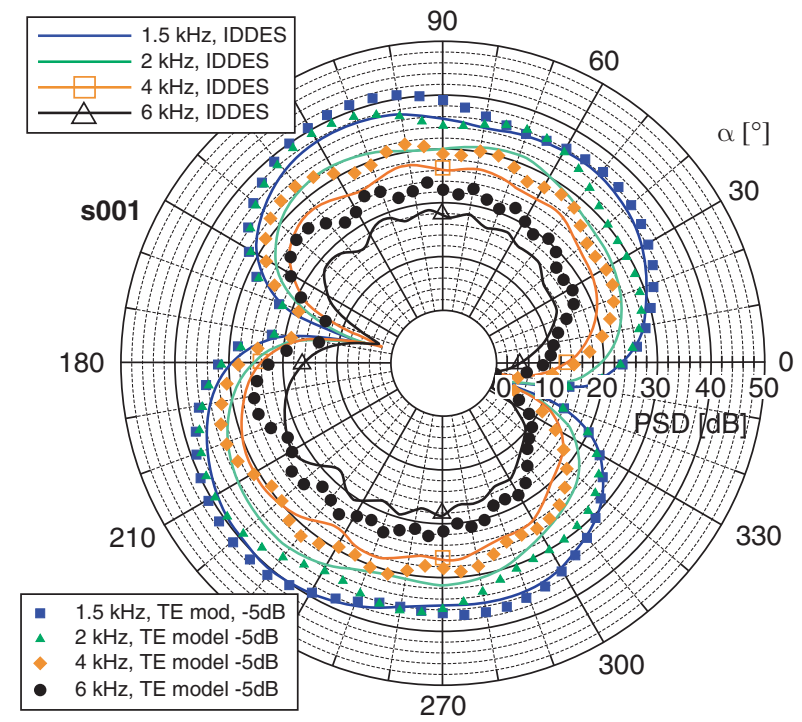

(b) Comparison TE model Rozenberg and IDDES

Figure 21: Far-field sound directivity for mid frequencies: $1.5 \mathrm{kHz}, 2 \mathrm{kHz}, 4 \mathrm{kHz}$ and $6 \mathrm{kHz}$, comparison to experiment and to TE model Rozenberg. 


\section{ACKNOWLEDGEMENT}

This study is a part of the EU funded $6^{\text {th }}$ Framework project PROBAND $n^{\circ}$ AST4-CT2005-012222.

\section{REFERENCES}

[1] Амiet, R. K.: Noise due to turbulent flow past a trailing edge. In: J. Sound Vib. 47 (1976), Nr. 3, S. 387-393.

[2] Bogey, C. ; BAILly, C.: Three-dimensional non-reflective boundary conditions for acoustic simulation: far field formulation and validation test cases. In: Acta Acoustica 88 (2002), S. 463-471.

[3] Camussi, R. ; Gennaro, G. C. ; Jacob, M.C. ; Grilliat, J.: Tip leakage flow experiment - part two: wavelet analysis of wall pressure fluctuations. In: Proceedings of $14^{\text {th }}$ AIAA/CEAS Aeroacoustic Conference. Roma, Italy, May 20-22 2007.

[4] CAMUSSI, R. ; ROBERT, G. ; JACOB, M.C.: Cross-wavelet analysis of wall pressure beneath incompressible turbulent boundary layers. In: J. Fluid Mech. 167 (2008), S. $11-30$.

[5] Coles, D: The law of the wake in the turbulent boundary layer. In: J. Fluid Mechanics 1 (1956), Nr. 2, S. 191-226.

[6] Farassat, F.: Theory of Noise Generation from Moving Bodies with Application to Helicopter Rotors / NASA. 1975 (TR-451). - Forschungsbericht.

[7] Ferziger, J. H. ; Peric, M.: Computational Methods for Fluid Dynamics, $3^{\text {rd }}$ rev. ed. Springer, 2002.

[8] Ffowcs-Williams, J. E. ; Hawkings, D. L.: Sound Generated by Turbulence and Surfaces in Arbitrary Motion. In: Philosophical Transactions of the Royal Society A264 (1969), S. 321-342.

[9] Goody, M.: Empirical spectral model of surface pressure fluctuations. In: AIAA J. 42 (2004), Nr. 9, S. 1788-1794.

[10] Greschner, B. ; Jacob, M. ; Casalino, D. ; Thiele, F.: Prediction of Sound generated by a rod-airfoil configuration using EASM DES and the generalised Lighthill/FW-H analogy. In: Computer \& Fluids, Turbulent Flow and Noise Generation 37 (2008), Nr. 4, S. 402-413.

[11] Grilliat, J. ; Jacob, M.C. ; CAmussi, R. ; Caputi-Gennaro, G.: Tip leakage flow experiment - part one: aerodynamic and acoustic measurements. In: Proceedings of $14^{\text {th }}$ AIAA/CEAS Aeroacoustic Conference. Roma, Italy, May 20-22 2007.

[12] HaAse, W. ; Aupoix, B. ; Bunge, U. ; Schwamborn, D.: FlOMANia: Flowphysics modelling - an integrated approach. Notes on Numerical Fluid Mechanics and Multidisciplinary Design. Springer Verlag, 2006.

[13] HoYAS, S. ; JIMÉNEZ , J.: Scaling of velocity fluctuations in turbulent channels up to $R e_{\tau}=2000$. In: Phys. of Fluids 18 (2006). 
[14] Jacob, M.C. ; Grilliat, J. ; Jondeau, E. ; Roger, M. ; ; CAmussi, R.: Broadband noise prediction models and measurements of tip leakage flows. In: Proceedings of $15^{\text {th }}$ AIAA/CEAS Aeroacoustic Conference. Vancouver, Canada, May 5-7 2008.

[15] Kato, C. ; Iida, A. ; TaKano, Y. ; FujtTA, H. ; IKegawa, M.: Numerical prediction of aerodynamic noise radiated from low mach turbulent wake. In: 31 st Aerospace Sciences Meeting and Exhibit. Reno, NV, January 1993.

[16] Lighthill, M. J.: On Sound Generated Aerodynamically, I: General Theory. In: Proceedings of the Royal Society London A221 (1952), S. 564-587.

[17] LuebcKe, H. ; Rung, T. ; ThiELE, F.: Prediction of spreading mechanism of $3 D$ turbulent wall jets with explicit Reynolds-stress closures. Bd. 5. S. 127-145, In Eng. Turb. Mod. \& Exp., 2002.

[18] Menter, F. R. ; Kunz, M.: Adaption of eddy-viscosity models to unsteady separated flow behind vehicles, R. McCallen, F. Browand, J. Ross: Lecture Notes in Applied and Computational Mechanics, 2004.

[19] Mockett, C. ; Greschner, B. ; Knacke, T. ; Perrin, R. ; Yan, J. ; Thiele, F.: Demonstration of improved DES methods for generic and industrial applications. In: Second Symposium on Hybrid RANS-LES methods. Corfu, Greece, 2007.

[20] Mockett, C. ; Thiele, F.: Overview of detached-eddy simulation for external and internal turbulent flow applications. In: New trends in fluid mechanics research: Proceedings of the fifth International Conference on Fluid Mechanics. Shanghai, China, 2007.

[21] Moreau, S. ; Henner, M. ; Iaccarino, G. ; Roger, M.: Analysis of flow conditions in free-jet experiments for studying self-noise. In: AIAA J. 41 (2003), Nr. 10, S. 1895-1905.

[22] Moreau, S. ; Roger, M.: Back-scattering correction and further extensions of Amiet's trailing-edge model. Part II: Application. In: J. Sound Vib. 323 (2009), S. 397-425.

[23] Roger, M. ; Moreau, S.: Back-scattering correction and further extensions of Amiet's trailing-edge model. Part I: theory. In: J. Sound Vib. 286 (2005), S. 477-506.

[24] Roger, M. ; Perennes, S.: Aerodynamic noise of two-dimensional wing with high-lift-devices. In: Proceedings of $4^{\text {th }}$ AIAA/CEAS Aeroacoustics Conference. Toulouse, France, June 1998.

[25] Rozenberg, Y. ; Roger, M. ; Guédel, A. ; Moreau, S.: Rotating blade self noise: experimental validation of analytical models. In: Proceedings of $13^{\text {th }}$ AIAA/CEAS Aeroacoustics Conference. Roma, Italy, May 2007.

[26] Rozenberg, Y. ; Roger, M. ; Moreau, S.: Fan blade trailing-edge noise prediction using RANS simulations. In: Proceedings of Acoustics 08 Euronoise. Paris, France, June $30^{\text {th }}-$ July $4^{\text {th }} 2008$.

[27] Rung, T. ; Eschricht, D. ; Yan, J. ; Thiele, F.: Sound Radiation of the Vortex Flow past a generic Side Mirror. In: Proceedings of $8^{\text {th }}$ AIAA/CEAS Aeroacoustics Conference Bd. 2340. Breckenridge, Colorado, June 2002. 
[28] Schloemer, H.H.: Effects of pressure gradients on turbulent boundary layer wall pressure fluctuations. In: J. Acoust. Soc. Am. 42 (1967), Nr. 1, S. 93-113.

[29] Schönwald, N. ; Schemel, C ; Eschricht, D. ; Michel, U. ; F., Thiele: Numerical Simulation of Sound Propagation and Radiation from Aero-Engine Intakes. In: Proceedings of the $3^{\text {rd }}$ Aeroacoustics Workshop SWING+. Stuttgart, Germany, September 2002.

[30] SeO, J.H. ; Moon, Y.J.: Aerodynamic noise prediction for long-span bodies. In: $J$. Sound Vib. 306 (2007), S. 564-579.

[31] Shur, M. L. ; Spalart, P. R. ; Strelets, M. K. ; Travin, A. K.: A hybrid RANSLES approach with Delayed-DES and wall-modelled LES capabilities. In: Int. J. of Heat and Fluid Flow 29 (2008), S. 1638-1649.

[32] Sparart, P. R. ; Jou, W. ; Strelets, M. K. ; Allmaras, S.: Comments on the feasibility of LES for wings and on a hybrid RANS/LES approach. Ruston, Lousiana, August 1997.

[33] Travin, A. K. ; Shur, M. L. ; Sparart, P. R. ; Strelets, M. K.: Improvement of Delayed Detached-Eddy Simulation for LES with Wall Modelling. In: Proceedings of ECCOMAS CFD 2006. Netherlands, Delft 2006.

[34] Travin, A. K. ; Shur, M. L. ; Strelets, M. K. ; Sparart, P. R.: Physical and numerical upgrades in the detached-eddy simulation of complex turbulent flows, W. Rodi, R. Friedrich: LES of complex transitional and turbulent flows, 2000.

[35] Wang, M. ; Moreau, S. ; IAcCarino, G. ; Roger, M.: LES prediction of wall pressure fluctuations and noise of a low speed airfoil. In: Proceedings of Acoustics 08, Euronoise. Paris, France, June $30^{\text {th }}-$ July $4^{\text {th }} 2008$. 
